\title{
Proton-coupled electron transfer from an interfacial phenol monolayer
}

\author{
Sjödin, Martin; Hjelm, Johan; Rutherford, A. William; Forster, Robert
}

Published in:

Journal of Electroanalytical Chemistry

Link to article, DOI:

10.1016/j.jelechem.2020.113856

Publication date:

2020

Document Version

Peer reviewed version

Link back to DTU Orbit

Citation (APA):

Sjödin, M., Hjelm, J., Rutherford, A. W., \& Forster, R. (2020). Proton-coupled electron transfer from an interfacial phenol monolayer. Journal of Electroanalytical Chemistry, 859, [113856].

https://doi.org/10.1016/j.jelechem.2020.113856

\section{General rights}

Copyright and moral rights for the publications made accessible in the public portal are retained by the authors and/or other copyright owners and it is a condition of accessing publications that users recognise and abide by the legal requirements associated with these rights.

- Users may download and print one copy of any publication from the public portal for the purpose of private study or research.

- You may not further distribute the material or use it for any profit-making activity or commercial gain

- You may freely distribute the URL identifying the publication in the public portal

If you believe that this document breaches copyright please contact us providing details, and we will remove access to the work immediately and investigate your claim 


\section{Journal Pre-proof}

Proton-coupled electron transfer from an interfacial phenol monolayer

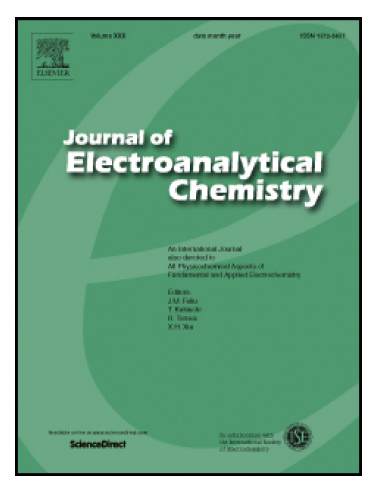

Martin Sjödin, Johan Hjelm, A. William Rutherford, Robert Forster

PII: $\quad$ S1572-6657(20)30039-4

DOI: $\quad$ https://doi.org/10.1016/j.jelechem.2020.113856

Reference: $\quad$ JEAC 113856

To appear in: Journal of Electroanalytical Chemistry

Received date: $\quad 30$ September 2019

Revised date: $\quad 3$ January 2020

Accepted date: $\quad 13$ January 2020

Please cite this article as: M. Sjödin, J. Hjelm, A.W. Rutherford, et al., Proton-coupled electron transfer from an interfacial phenol monolayer, Journal of Electroanalytical Chemistry(2020), https://doi.org/10.1016/j.jelechem.2020.113856

This is a PDF file of an article that has undergone enhancements after acceptance, such as the addition of a cover page and metadata, and formatting for readability, but it is not yet the definitive version of record. This version will undergo additional copyediting, typesetting and review before it is published in its final form, but we are providing this version to give early visibility of the article. Please note that, during the production process, errors may be discovered which could affect the content, and all legal disclaimers that apply to the journal pertain.

(C) 2020 Published by Elsevier. 


\title{
Proton-Coupled Electron Transfer from an
}

\section{Interfacial Phenol Monolayer}

\author{
Martin Sjödin ${ }^{a, 1^{*}}$, Johan Hjelm ${ }^{b, 2}$, A. William Rutherford ${ }^{a, 3}$ and Robert Forster ${ }^{b}$ \\ ${ }^{\text {a } I n s t i t u t ~ d e ~ B i o l o g i e ~ e t ~ d e ~ T e c h n o l o g i e s ~ d e ~ S a c l a y, ~ S e r v i c e ~ d e ~ B i o e ́ n e r g e t i q u e ~ B i o l o g i e ~}$ \\ Structurale et Méchanismes, Commisariat à l'Energie Atomique, Saclay Bât 532, FR-91191 \\ Gif-sur-Yvette, France (a.rutherford@imperial.ac.uk and martin.sjodin@angstrom.uu.se) \\ ${ }^{\mathrm{b}}$ School of Chemical Sciences, National Center for Sensor Research, SFI Research Centre for \\ Chronic and Rare Neurological Diseases, FutureNeuro, Dublin City University, Dublin 9, \\ Ireland (robert.forster@dcu.ie and johh@dtu.dk) \\ * Corresponding author: Martin Sjödin (martin.sjodin@angstrom.uu.se)
}

Present Address: Nanotechnology and Functional Materials, Department of Engineering Sciences, The Ångström Laboratory, Uppsala University, Box 534, SE-751 21 Uppsala, Sweden.

\footnotetext{
${ }^{1}$ Present address: Nanotechnology and Functional Materials, Department of Engineering Sciences, The Ångström Laboratory, Uppsala University, Box 534, SE-751 21 Uppsala, Sweden.

${ }^{2}$ Present address: DTU Energy, Department of Energy Conversion and Storage, Technical University of Denmark, 4000 Roskilde, Denmark

${ }^{3}$ Imperial College London, Department of Life Sciences, London, UK
} 


\section{Highlights}

- The pH-dependent mechanism and dynamics of proton coupled redox reactions from an alkane thiol monolayer with phenol head groups is revealed.

- A novel, non-pre-equilibrium model (Steady-state model) accurately describes the kinetics of proton coupled redox reactions and the scan-rate dependent current response in cyclic voltammetry.

- The presented model presents an alternative approach to describing surface confined proton coupled electron transfer reactions where proton transfer reactions are cannot be assumed to be fast in relation to the electron transfer reactions.

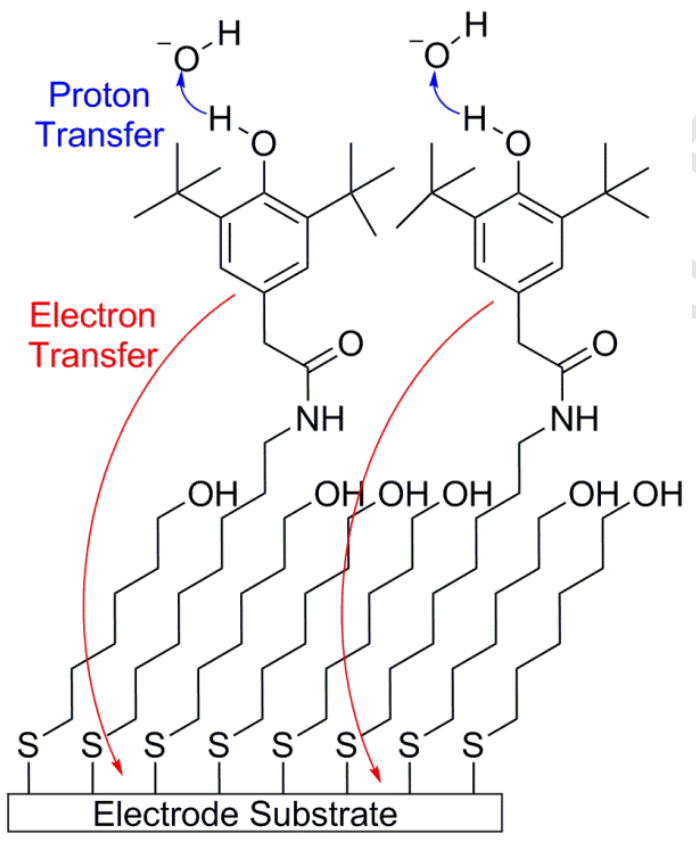

\section{Graphical Abstract}




\section{Abstract}

A tert-butyl protected phenol is covalently link to a mixed self-assembled monolayer on a gold or platinum electrode. The phenol reduction potential shows the expected $\mathrm{pH}-$ dependence of a one-electron, one-proton couple with a decrease in formal reduction potential of $59 \pm 5 \mathrm{mV}$ per $\mathrm{pH}$. A titration of the phenol is observed with a $\mathrm{pK}_{\mathrm{a}}$ of 13.2 and the reduction potential for the phenolate is $0.11 \mathrm{~V}$ vs. NHE. The kinetic behavior of the proton-coupled oxidation deviates substantially from the commonly used models for a step-wise reaction that assume the proton transfer reactions are in equilibrium throughout the reaction. A novel model for step-wise proton-coupled reactions is presented that fully accounts for the $\mathrm{pH}$ dependent kinetics and allows the formal rate constants and the transfer coefficients to be determined.

KEYWORDS: Phenol-terminated alkane-thiol monolayer, Proton-coupled electron transfer, pH dependence, Kinetic models.

\section{Introduction}

Proton-coupled electron transfer reactions are of great importance in a variety of biological and chemical processes. [1-4] The coupled reaction can proceed either in a stepwise or a concerted fashion. In the stepwise case, the proton-transfer occurs either prior to, or after the electron transfer reaction while in the concerted reaction the two processes share a unique transition state and are thus simultaneous. Recently, significant attention has been devoted to the relative importance of these reaction mechanisms and experimental tools for mechanistic discrimination have been developed and debated. [5-9]

In this report we have used a redox active phenol moiety as model to study proton-coupled electron transfer by electrochemical means. Due to its structural homology with tyrosine, 
which is known to be important as a redox intermediate in several radical proteins including Photosystem II[10], DNA photolyase[11], ribonucleotide reductase[1] and cytochrome c oxidase[12], this model compound is of particular interest. The phenol radical was stabilized by tert-butyl substituents in ortho-position and a carboxylate functionality in the para-position was used to covalently attach the phenol onto an amine terminated alkane thiol layer on platinum or gold using a peptide linkage. The phenols were diluted with alcohol terminated thiols to form the system depicted in Figure 1. Immobilizing the phenol avoids mass transfer limitations which simplifies the kinetic analyses. The use of alkane thiol linkers for surface attachment makes it possible to tune the rates of the redox reaction by varying the length of the thiol spacer. With the densely packed alkane thiol monolayer, double layer effects are also minimized and the low capacitance of these layers reduces the response time of the electrochemical set-up. [13]

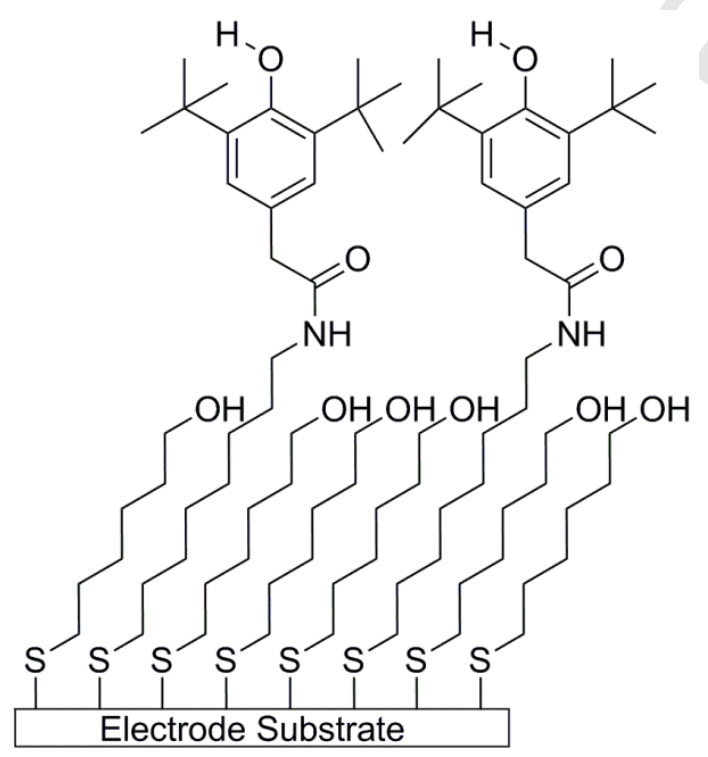

Figure 1. Schematic illustration of monolayers of 2,6-Di-tert-butyl-phenol attached to a metal substrate via an amide link to a alkane thiol. The phenol monolayer was diluted 20 fold with 6-mercapto-1-hexanol. Gold or platinum was used as substrate electrode. 
The proton-coupled electron transfer reaction from the phenol is schematically depicted in Scheme 1. Two step-wise reactions that convert the protonated phenol to the deprotonated phenol radical can be envisioned, one in which the phenol first deprotonates forming a phenolate ion that is subsequently oxidized and another path where the primary step is the oxidation of the phenol forming the protonated phenol radical that deprotonates as a consequence of the oxidation. The first of these reaction paths is expected to dominate the kinetics at high $\mathrm{pH}$ where a significant fraction of phenolates are accessible, whilst the second reaction path dominates at low $\mathrm{pH}$.

To treat the kinetics of electrochemically-driven, surface-confined proton-coupled electron transfers, and specifically the $\mathrm{pH}$ dependence of the reaction, a model is often adopted in which it is assumed that the proton transfer reactions are rapid compared to the electron transfer reactions. This model was originally developed by Laviron[14-18] and it has been used to successfully model the kinetics of proton-coupled electron transfer reactions in a variety of systems. [19-22] The model has also been extended by the work of Finklea et.al. to include the influence of a potential-dependent transfer coefficient as predicted from the Marcus density-of-states model. [23-25] Within this model, the overall rate constant is given by the fraction of the intermediate species, the phenolate and the protonated radical, relative to its proton equilibrium counterpart, multiplied by the rate constant for the relevant redox reaction. The apparent exchange rate constant at the formal potential shows a deep minimum at $\mathrm{pHs}$ between the $\mathrm{pK}_{\mathrm{a}}$-values for the reduced and the oxidized species. At $\mathrm{pH}$ values above the minimum, the reaction is dominated by the phenolate path and at $\mathrm{pH}$ values below the minimum it is dominated by the protonated radical route. The steepness of the $\mathrm{pH}$ response is controlled by both the $\mathrm{pH}$ dependent species present and the dependence of the electron transfer rate constant on $\mathrm{pH}$. 


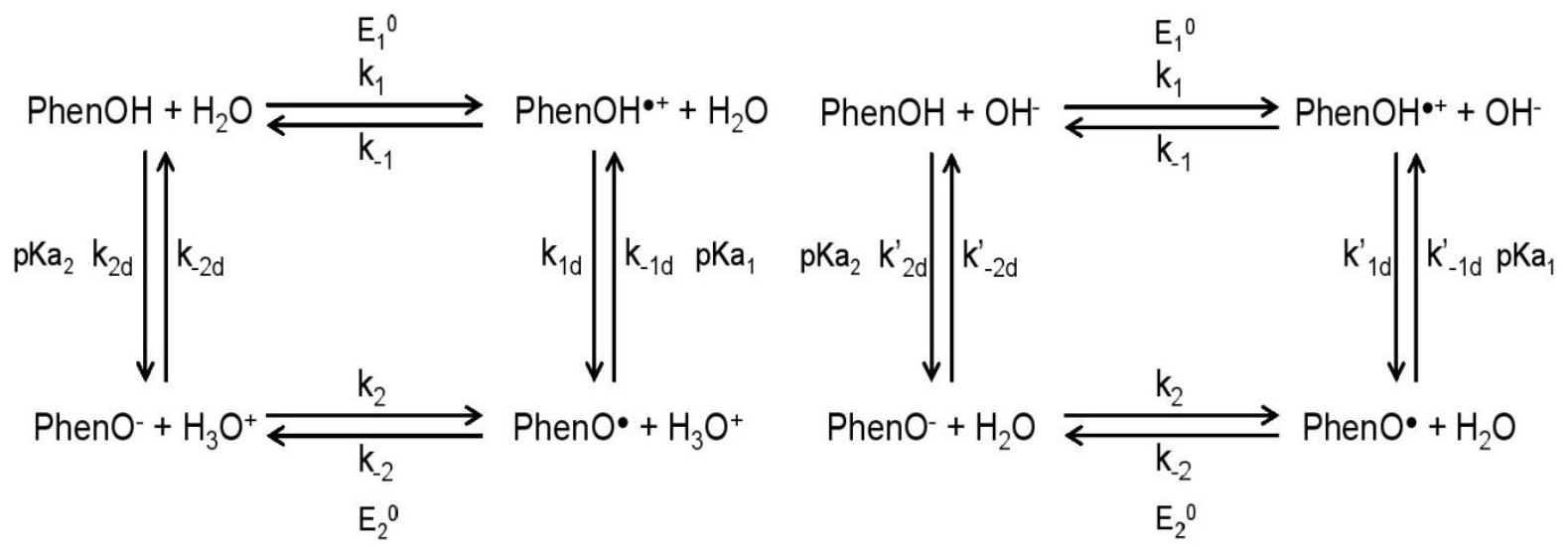

\section{Scheme 1. Reaction Scheme for proton-coupled redox reaction of phenol monolayers}

Although the proton equilibrium model has been highly successful in interpreting surfaceconfined proton-coupled redox reactions, the assumption that proton transfer reactions are fast compared to the electron transfer reactions, is often questionable. For the proton transfer reactions two equilibria need to be considered as depicted in Scheme 1. At low pH the phenol dissociation equilibrium is dominated by deprotonation to $\mathrm{H}_{2} \mathrm{O}$ and protonation by $\mathrm{H}_{3} \mathrm{O}^{+}$(left panel Scheme 1) and the dissociation constant $\left(\mathrm{K}_{\mathrm{a}}\right)$ is given by Equation 1 where $\mathrm{k}_{2 \mathrm{~d}}$ is the rate constant for deprotonation to $\mathrm{H}_{2} \mathrm{O}$ and $\mathrm{k}_{-2 \mathrm{~d}}$ the protonation by $\mathrm{H}_{3} \mathrm{O}^{+}$.

$$
\mathrm{K}_{\mathrm{a}}=\mathrm{k}_{2 \mathrm{~d}} / \mathrm{k}_{-2 \mathrm{~d}}
$$

For an exergonic proton transfer between two Eigen-acids with sufficiently different $\mathrm{pK}_{\mathrm{a}}$ values, typically one $\mathrm{pH}$ unit, the rate of proton transfer non-activated and the reaction is diffusion controlled. [26-28] Consider for instance the protonation of a phenolate, for which the corresponding phenol typically has a $\mathrm{pK}_{\mathrm{a}}$ value around 10 [29], by $\mathrm{H}_{3} \mathrm{O}^{+}$, which has a $\mathrm{pK}_{\mathrm{a}}$ value of -1.7 [27] ( $\mathrm{k}_{-2 \mathrm{~d}}$ in Scheme 1). This reaction is expected to de diffusion controlled. Given the high mobility of the proton, the rate constant $\left(k_{-2 \mathrm{~d}}\right)$ is on the order of $10^{11} \mathrm{M}^{-1} \mathrm{~s}^{-1}$. 
From Equation 1 the corresponding deprotonation rate constant $\left(\mathrm{k}_{2 \mathrm{~d}}\right)$ is $10 \mathrm{~s}^{-1}$ which is readily exceeded by the observed rate constant in many electrochemical measurements.

At high $\mathrm{pH}$, the phenol dissociation reaction is instead dominated by deprotonation to $\mathrm{OH}^{-}$ and protonation by $\mathrm{H}_{2} \mathrm{O}$ (right panel Scheme 1). In this case the deprotonation reaction is expected to be diffusion controlled given that the $\mathrm{pK}_{\mathrm{a}}$ value for water is 15.7. [27] The lower mobility of $\mathrm{OH}^{-}$compared to $\mathrm{H}_{3} \mathrm{O}^{+}$gives an order of magnitude lower diffusion controlled rate constant and $\mathrm{k}_{2 \mathrm{~d}}$ ' is expected to be on the order of $1 * 10^{10} \mathrm{M}^{-1} \mathrm{~s}^{-1}$. At $\mathrm{pH} 7$, for instance, the concentration of $\mathrm{OH}^{-}$is $10^{-7} \mathrm{M}$ and the rate of deprotonation by $\mathrm{OH}^{-}$can be estimated to $10^{3} \mathrm{~s}^{-1}$. Also this rate is often surpassed by surface-confined redox reactions. From the equilibrium condition (Equation 2) the rate constant for protonation by water $\left(\mathrm{k}_{-2 \mathrm{~d}}\right.$ ') is expected to be on the order of $1 * 10^{6} \mathrm{~s}^{-1}$ for a phenol with a pKa of 10 . In Equation $2 \mathrm{~K}_{\mathrm{w}}$ is the auto-protolysis constant for water.

$$
\mathrm{K}_{\mathrm{a}} / \mathrm{K}_{\mathrm{w}}=\mathrm{k}_{2 \mathrm{~d}} / \mathrm{k}_{-2 \mathrm{~d}}{ }^{\prime}
$$

From the discussion above it is clear that the proton-equilibrium model does not apply at all $\mathrm{pH}$ values in proton-coupled redox systems, in particular where reactants with high $\mathrm{pK}_{\mathrm{a}}$ values are involved. We have therefore adopted a steady-state approach to rationalize the kinetics of proton-coupled electron transfers in the phenol monolayers depicted in Figure 1. In this model, the assumption is that in a kinetically controlled reaction the concentration of the intermediate species in Scheme 1 is never built up, i.e., the rate of intermediate state production is always less than the rate of reactions consuming it. With this assumption, analytical expressions for electrochemical responses have been derived and used in the kinetic analysis. For comparative reasons kinetic data have also been analyzed using the proton equilibrium model. 


\section{Experimental Section}

All chemicals were purchased and used as received. For all solutions distilled deionized water with a resistivity above $18 \mathrm{M} \Omega \mathrm{cm}$ or anhydrous ethanol (Sigma Aldrich) was used.

\subsection{Electrode fabrication}

Platinum or gold disc electrodes were prepared by sealing a $100 \mu \mathrm{m}$ radius platinum wire (Goodfellow) or a $125 \mu \mathrm{m}$ radius gold wire (Goodfellow) in a soft glass tube. The end of the glass tube was first melted to give a small opening at one end of the tube. After sonicating the tube in acetone for $10 \mathrm{~min}$ and evaporation of the acetone from the tube the metal wire, attached to a $1 \mathrm{~mm}$ copper substrate wire, was fit into the melted end of the glass tube and was sealed into the glass by melting the glass around the metal. The open end of the glass tube, where the substrate copper wire was protruding, was sealed using a plastic cap and epoxy glue. The metal disc electrodes were exposed by sanding on 500 grit paper followed by successive polishing with $1,0.3$ and $0.05-\mu \mathrm{m}$ alumina (Buehler) water slurry.

\subsection{Monolayer preparation}

Electrodes were first polished with $0.05 \mu \mathrm{m}$ alumina, rinsed with water and sonicated for one minute in water. The electrodes were then electrochemically cleaned in $0.5 \mathrm{M} \mathrm{H}_{2} \mathrm{SO}_{4}$ (Sigma-Aldrich $99.999 \%$ ) by cycling the potential between $-0.2 \mathrm{~V}$ and $1.45 \mathrm{~V}$ for platinum electrodes and between -0.25 and $1.5 \mathrm{~V}$ vs. $\mathrm{Ag} / \mathrm{AgCl}$ saturated with $\mathrm{KCl}$ for gold electrodes. The reference electrode was kept in a compartment separated from the cleaning solution by a porous glass frit. Estimates of the real surface areas of the electrodes were made from the metal oxide reduction wave from voltammetric scans between -0.15 and 1.35 for platinum 
electrodes and -0.25 and 1.45 for gold electrodes. The roughness factor was typically between 1.5 and 2.5. [30]

Immediately after the electrochemical cleaning, the electrodes were rinsed with water then ethanol and were immersed into $10 \mathrm{mM}$ thiol deposition solution. The deposition solution was either a 1:20 mixture of 8-Amino-1-octanethiol and 6-mercapto-1-hexanol or pure 6mercapto-1-hexanol. The 6-mercapto-1-hexanol covered electrodes served as backgrounds and one background electrode was prepared for each electrode with mixed thiol composition.

After at least 3 hours of coupling the mixed composition electrodes were rinsed with ethanol and were transferred to a peptide linkage solution composed of $40 \mathrm{mM}$ 3,5-Di-tertbutyl-4-hydroxyphenylacetic acid (Alfa Aesar) and 1.8 M N-(3-Dimethylaminopropyl)-N'Ethylcarbodiimide (Sigma-Aldrich) in ethanol. To one $\mathrm{mL}$ of this solution 1 drop $1 \mathrm{M} \mathrm{KOH}$ was added. The addition of $\mathrm{KOH}_{\mathrm{aq}}$ was found to enhance the reaction yield and to speed up the reaction significantly. The peptide reaction was left to proceed for 3 hours, the electrodes were then rinsed with ethanol and transferred to a $10 \mathrm{mM}$ 6-mercapto-1-hexanol solution and left overnight to improve packing of the monolayer. Also the background electrodes were left overnight in the coupling solution.

\subsection{Electrochemical measurements}

All electrochemical measurements were made in $0.1 \mathrm{M} \mathrm{K}_{2} \mathrm{SO}_{4}$ solution buffered with 10 $\mathrm{mM} \mathrm{H}_{3} \mathrm{BO}_{3}$ (Sigma Aldrich) and $10 \mathrm{mM} \mathrm{Na}_{2} \mathrm{HPO}_{4}$ (Sigma-Aldrich). The $\mathrm{pH}$ was adjusted using concentrated sulfuric acid or potassium hydroxide. To remove dissolved oxygen the electrolyte solution was purged with argon prior to measurement and was kept under an argon atmosphere throughout the measurement.

A conventional three electrode system was used in a single compartment. $\mathrm{An} \mathrm{Ag} / \mathrm{AgCl}$ electrode with saturated $\mathrm{KCl}$ was used as reference. To facilitate comparison, all reported 
potentials were converted to the normal hydrogen electrode scale by adding $0.197 \mathrm{~V}$ to the measured potential. The phenol covered platinum or gold disc electrodes and the corresponding 6-mercapto-1-hexanol covered electrodes (see above) constituted the working electrodes and a platinum wire served as the counter electrode. To correct for uncompensated resistance in the cell, AC impedance measurements between 10 and $10000 \mathrm{~Hz}$ were made and the resistance were typically evaluated to be around $300 \Omega$. All potentials applied to the phenol monolayer were corrected for uncompensated resistance and the same correction was used for the 6-mercapto-1-hexanol layers to enable subtraction of capacitive currents. Since the 6-mercapto-1-hexanol layers gave a rather flat baseline for subtraction the error introduced by this procedure should be minor.

All data were collected using a CHI660C Electrochemical workstation (CH-Instruments) and CVs were collected at scan rates between 0.1 and $20000 \mathrm{Vs}^{-1}$ with typically 1000 data points per $\mathrm{CV}$. The lower scan rates were used to characterize the phenol monolayer while higher scan rates were used to get kinetic information on the phenol oxidation. All kinetic CVs were corrected for uncompensated resistance, the capacitive current was subtracted and the resulting voltammograms were analyzed in Origin by fitting the CVs to the models described below while the low scan rate $\mathrm{CV}$ s were analyzed in the software provided by $\mathrm{CH}$ Instruments. The reported data are from fully reproducible voltammograms from multiple consecutive scans centred on the recorded redox process. 


\section{Results and discussion}

\subsection{Monolayer Characterization}

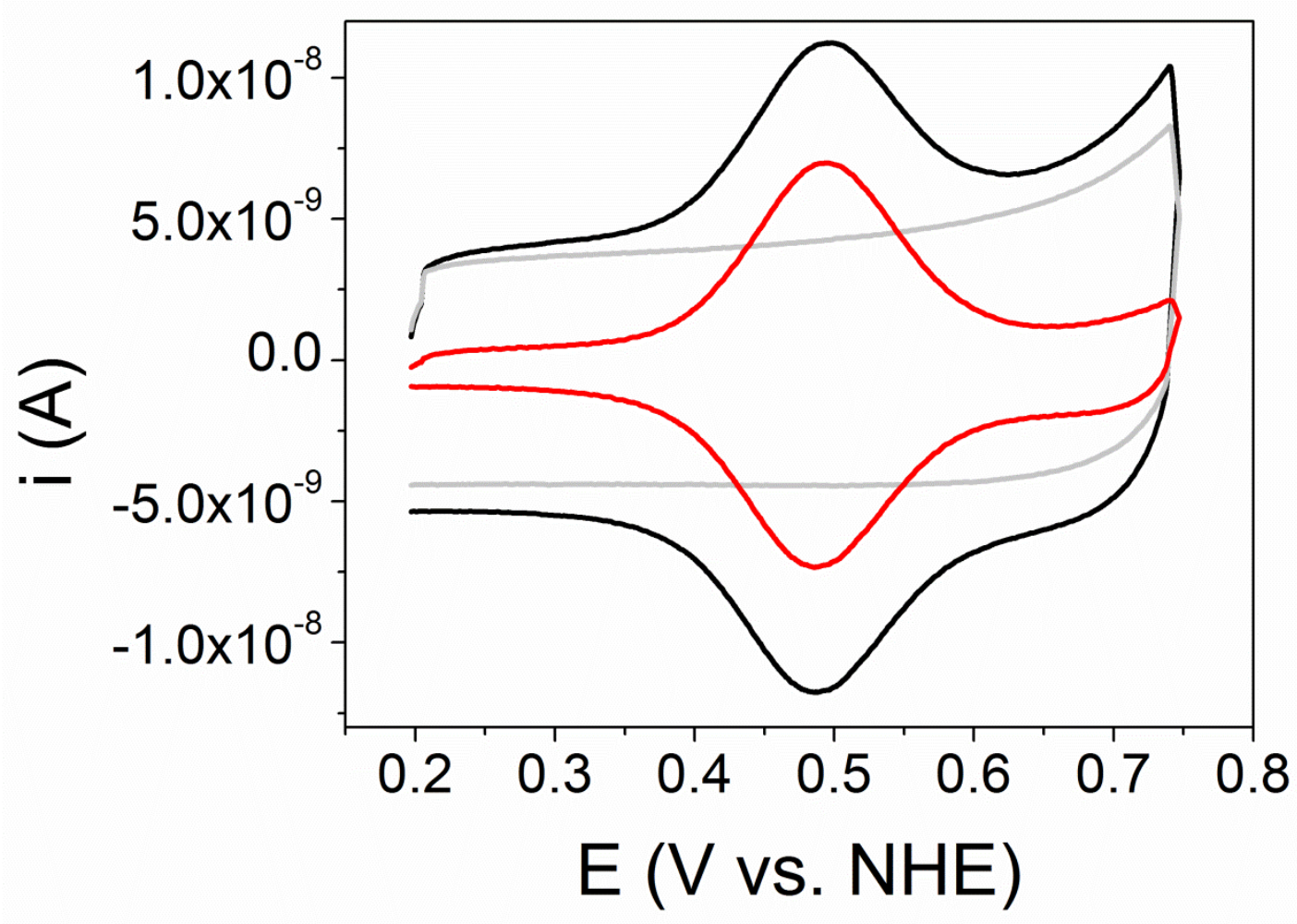

Figure 2. Cyclic voltammetry at $1 \mathrm{Vs}^{-1}$ of a gold electrode covered with phenol monolayer (black), 6-mercapto-1-hexanol monolayer (grey) and the background subtracted response (red) in $0.1 \mathrm{M} \mathrm{K}_{2} \mathrm{SO}_{4}$ buffered with $10 \mathrm{mM} \mathrm{Na}_{2} \mathrm{HPO}_{4}$ and $\mathrm{H}_{3} \mathrm{BO}_{3}$ and adjusted to $\mathrm{pH} 10.3$ with $\mathrm{KOH}_{\mathrm{aq}}$. The surface coverage was evaluated from the peak area and the microscopic electrode area $\left(1.2 * 10^{-3} \mathrm{~cm}^{2}\right)$ as $1.9 * 10^{-11} \mathrm{~mol} \mathrm{~cm}$.

Figure 2 shows a typical cyclic voltammogram at $1 \mathrm{Vs}^{-1}$ of the phenol monolayer depicted in Figure 1 on a gold electrode together with a voltammograms from a 6-mercapto-1-hexanol covered electrode at $\mathrm{pH}$ 10.3. Subtraction of the response from the 6-mercapto-1-hexanol layer removes a significant fraction of the background capacitance. (The somewhat higher capacitance of the phenol layer might be due to a decreased monolayer packing due to the 
introduction of the phenol-functionalized thiols). At this scan rate the peak separation between the oxidation and the reduction wave is close to $0(7 \mathrm{mV})$ and is reduced to zero at even lower scan rates $\left(0.1 \mathrm{Vs}^{-1}\right)$ as expected for fully reversible redox reactions. The full width at half maximum for both the oxidation wave and the reduction wave was significantly larger than the expected $90.6 \mathrm{mV}$ for a fully reversible one-electron reaction. This was found at all scan rates and $\mathrm{pH}$ values investigated and it suggests thermodynamic heterogeneity, interaction between the redox centers or double layer effects.[13] The origin of this non-ideal behavior has however not been pursued further in this work.

From the peak area and the estimated real electrode area the surface coverage of the phenol was estimated to $1.9 * 10^{-11} \mathrm{~mol} \mathrm{~cm}{ }^{-2}$. By reductive desorption of the thiol layer in $0.1 \mathrm{M} \mathrm{KOH}$ the total amount of thiols on the surface was estimated to $9.1 * 10^{-10} \mathrm{~mol} \mathrm{~cm}^{-2}$. [31] $2 \%$ of the thiols on the surface are thus functionalized with phenols. Since the 8-Amino-1-octanethiol and the diluting 6-mercapto-1-hexanol are of similar size and are expected to have similar diffusion constants an approximate estimate of the surface composition can be made from the composition of the coupling solution, i.e. 8-Amino-1-octanethiol:6-mercapto-1-hexanol 1:20. ${ }^{[32,33]}$ The maximum phenol surface coverage is therefore $4.55^{*} 10^{-11} \mathrm{molcm}^{-2}$ and hence the peptide reaction yield is about $40 \%$. This is however an underestimation of the yield since the thiol monolayers are known to exchange slowly with thiols in solution and therefore, when the phenol covered electrodes are immersed in the 6-mercapto-1-hexanol solution for improved packing, some losses of phenols are expected. [34] 


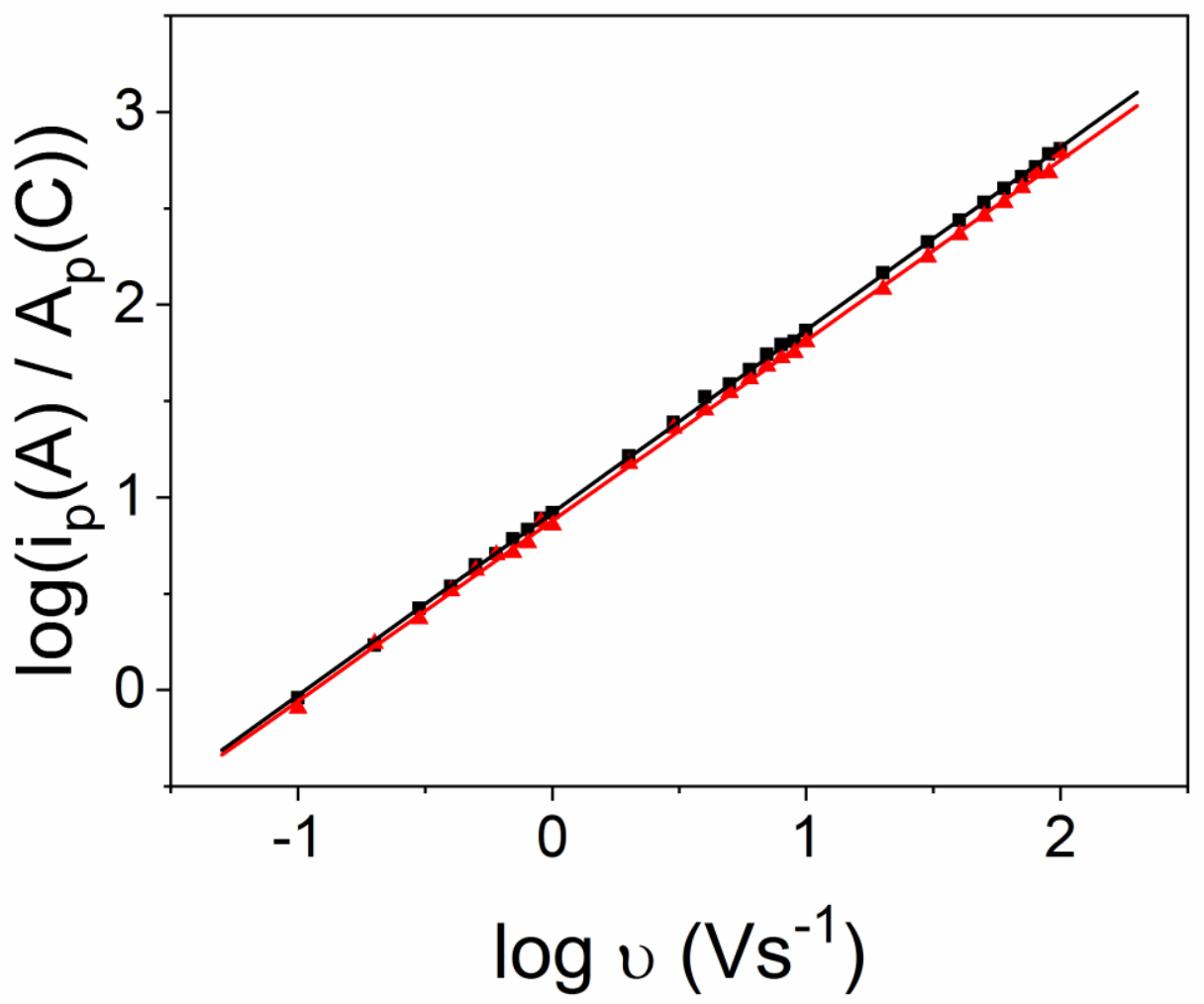

Figure 3. Absolute peak current normalized to the peak area as function of the logarithm of the scan rate between 0.1 and $100 \mathrm{Vs}^{-1}$. The conditions were the same as in Figure 2. Black squares correspond to the phenol oxidation and red triangles to the reduction. The solid lines are linear fits to the data and the evaluated slopes were 0.98 and 0.97 for the oxidative data and the reductive data respectively.

At scan rates below $10 \mathrm{Vs}^{-1}$ loss of surface coverage was observed indicating instability of the phenol radical. Below $1 \mathrm{Vs}^{-1}$ this loss was severe and the effect was also more pronounced at low $\mathrm{pH}$ thus limiting the useful $\mathrm{pH}$ range. To account for the loss of surface coverage the peak currents in Figure 3 have been normalized to the peak area. With this correction made the logarithm of the peak currents show a linear increase with the logarithm of the scan rate up to $100 \mathrm{Vs}^{-1}$ and the slope was close to 1 at all $\mathrm{pH}$ investigated as expected for a surface confined redox reaction. By changing the scan rate, the relative influences of the rates of 
electron and proton can be changed. At higher scan rates this linear increase in peak current with scan rate was no longer observed and at lower $\mathrm{pH}$ the onset of non-linearity occurred at lower scan rates. The origin of the non-linear dependence of the peak current with scan rate is discussed below.

\section{$3.2 \mathrm{pH}$ dependence of the formal reduction potential}

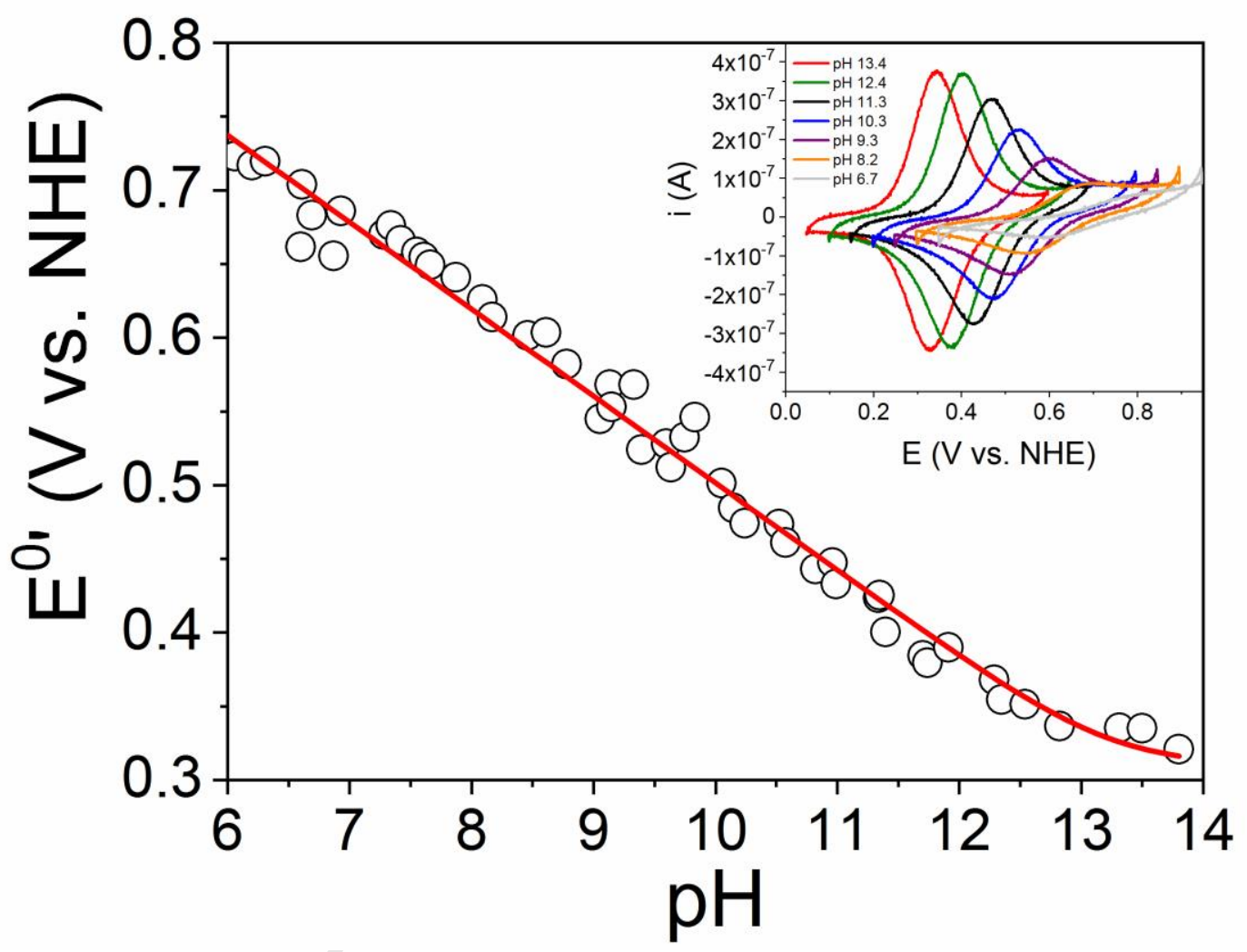

Figure 4. pH dependence of the formal potentials evaluated from cyclic voltammograms of a phenol monolayer together with a fit to Equation 3. The inset shows background subtracted cyclic voltammograms from phenol monolayers at pH 13.4 (red), 12.4 (green), 11.3 (black), 10.4 (blue), 9.3 (purple), 8.2 (orange) and 6.7 (grey) recorded at 50 $\mathrm{Vs}^{-1}$ in $0.1 \mathrm{M} \mathrm{K}_{2} \mathrm{SO}_{4}$ buffered with $10 \mathrm{mM} \mathrm{Na}_{2} \mathrm{HPO}_{4}$ and $\mathrm{H}_{3} \mathrm{BO}_{3}$. 
Figure 4 illustrates the effect of $\mathrm{pH}$ on the phenol redox chemistry. As the $\mathrm{pH}$ is decreased, the redox wave moves towards higher potentials. Also, the peak separation between the oxidation wave and the reduction wave increases, indicating that the rate constant for the redox reaction decreases, and the redox wave becomes broader at lower $\mathrm{pH}$.

$$
E^{0^{\prime}}=E_{1}^{0}+\frac{R T \ln 10}{n F} \log \frac{1+10^{p H-p K a_{2}}}{1+10^{p H-p K a_{1}}}
$$

For a one-proton, one-electron proton-coupled redox reaction, the formal reduction potential is expected to depend on $\mathrm{pH}$ according to Equation 3, [35] where the symbols are as defined in Scheme 1. In the $\mathrm{pH}$ region between the $\mathrm{pK}_{\mathrm{a}}$-values for the oxidized and the reduced form the formal potential decreases linearly with $\mathrm{pH}$ with a slope of $59 \mathrm{mV}$ per $\mathrm{pH}$. At $\mathrm{pH}$ values above the $\mathrm{pK}_{\mathrm{a}}$-value for the reduced form and below the $\mathrm{pK}_{\mathrm{a}}$ value for the oxidized state the potential becomes $\mathrm{pH}$ independent as the redox reaction is no longer coupled to proton transfer. By fitting the redox data in Figure 4 to Equation 3, the $\mathrm{pK}_{\mathrm{a}}$ value for the reduced phenol-form was estimated to be 13.2. (In the fit, $\mathrm{pKa}_{1}$ was set to 0 ). No indication of a low-pH plateau was observed in the $\mathrm{pH}$-range investigated. This was not unexpected since the phenol radical is known to be very acidic.[36, 37] The reduction potential for phenolate oxidation $\left(\mathrm{E}_{2}{ }^{0}\right)$ was evaluated to $0.11 \mathrm{~V}$ vs. NHE and the standard potential for phenol oxidation was evaluated to $0.89 \mathrm{~V}$ vs. NHE from extrapolation of the formal potential to $\mathrm{pH} 0$, i.e. when the proton activity is 1 and hence at standard state.

\subsection{Evaluation of kinetic parameters using a pre-equilibrium approach}

For proton-coupled redox reactions it is often assumed that the proton transfer reactions depicted in Scheme 1 are at equilibrium at all times during the redox conversion and this model has been very successful in evaluating kinetic data for these types of reactions. Since the protonation and deprotonation reactions are assumed to be fast compared to the electron 
transfer reactions, equilibrium constants rather than rate constants can be used for the proton transfer steps. This has the advantage that the equilibrium constants are often known from the $\mathrm{pK}_{\mathrm{a}}$ values of the species involved. Table 1 lists the analytical expressions for the peak current and for the peak over-potential as function of scan rate for a kinetically controlled surfaceconfined proton-coupled redox reaction. An experimental criterion for a kinetically controlled reaction has previously been identified as being scan rates at which the peak over-potential is more than $100 \mathrm{mV}$ [38] and this criterion has been used throughout the analysis in the present study. The expression for the peak over-potential, given in Table 1, predicts a linear dependence on the peak over-potential with the logarithm of the scan rate and can be used to evaluate kinetic parameters for the proton-coupled redox reaction. Note that in this Equation $\mathrm{k}^{0^{\prime}}$ is the $\mathrm{pH}$-dependent formal exchange rate constant and not the standard rate constants $\mathrm{k}_{2}^{0}$ or $\mathrm{k}^{0}{ }_{1}$ depicted in Scheme 1 for the non-proton-coupled redox reaction. Within the preequilibrium model, these constants are however related by Equation 4 where $\alpha_{1}$ and $\alpha_{2}$ are the transfer coefficients for the redox reaction between fully protonated species and fully deprotonated species respectively and $\mathrm{k}_{1}^{0}$ and $\mathrm{k}_{2}^{0}$ are the corresponding standard rate constants.

$k^{0^{\prime}}=\frac{k_{1}^{0}\left(\frac{1+10^{p H-p K a_{2}}}{1+10 p H-p K a_{1}}\right)^{1-\alpha_{1}}+k_{2}^{0}\left(\frac{1+100^{p K a_{2}-p H}}{1+10 p H-p H}\right)^{1-\alpha_{2}} 10^{p H-p K a_{2}}}{1+10^{p H-p K a_{2}}}$ 4

In the phenol system studied here, the $\mathrm{pK}_{\mathrm{a}}$ value for the phenol radical $\left(\mathrm{pKa}_{1}\right)$ is expected to be very low. In this case Equation 4 can be simplified to Equation 5 since the first term can be neglected and the numerator in the second term simplified.

$$
k^{0^{\prime}}=\frac{k_{2}^{0}}{\left(1+10^{p K a_{2}-p H}\right)^{\alpha_{2}}}
$$


Table 1. Analytical expressions for the peak current and the peak over-potential for the pre-equilibrium model and for the steady state model describing the cyclic voltammetry responses for a kinetically controlled, surface-confined proton-coupled redox reaction. In the Equations $\Gamma$ is the surface coverage, $A$ the electrode area, $v$ the scan rate, $\mathrm{k}^{0}$ ' the formal exchange rate constant $\mathrm{k}_{2}{ }^{0}$ the standard rate constant, $k_{2 d}$ the deprotonation rate constant, and $\mathrm{k}_{-2 \mathrm{~d}}$ is the protonation rate constant. Other parameters have their usual meaning.

\begin{tabular}{lcc}
\hline & Peak Current (A) & $\mathbf{E}_{\mathbf{p}}-\mathbf{E}^{\mathbf{O}^{\prime}} \mathbf{( \mathbf { V } )}$ \\
\hline $\begin{array}{l}\text { Pre-Equilibrium } \\
\text { model } \\
\text { (Oxidative Scan) }\end{array}$ & $\frac{(1-\alpha) n A F^{2} \Gamma v}{2.718 R T}$ & $\frac{R T}{(1-\alpha) n F} \ln \frac{(1-\alpha) n F}{R T k^{0^{\prime}}}-\frac{R T}{(1-\alpha) n F} \ln v$ \\
$\begin{array}{l}\text { Pre-Equilibrium } \\
\text { model }\end{array}$ & $-\frac{\alpha n A F^{2} \Gamma v}{2.718 R T}$ & $-\frac{R T}{\alpha n F} \ln \frac{\alpha n F}{R T k^{0^{\prime}}}-\frac{R T}{\alpha n F} \operatorname{lnv}$ \\
$\begin{array}{l}\text { (ReductiveScan) } \\
\begin{array}{l}\text { Steady State } \\
\text { model } \\
\text { (Oxidative scan) }\end{array}\end{array}$ & $\frac{F A \Gamma_{R e d}^{0} k_{2 d}(1-\alpha) F v}{R T k_{2 d}+(1-\alpha) F v}\left[1+\frac{(1-\alpha) F v}{R T k_{2 d}}\right]^{-\frac{R T k_{2 d}}{(1-\alpha) F v}}$ & $E_{2}^{0}-\frac{R T}{(1-\alpha) F} \ln \frac{k_{2}^{0} R T k_{2 d}}{(1-\alpha) F v k_{2 d} 10^{p K a_{2}-p H}}$ \\
\hline
\end{tabular}




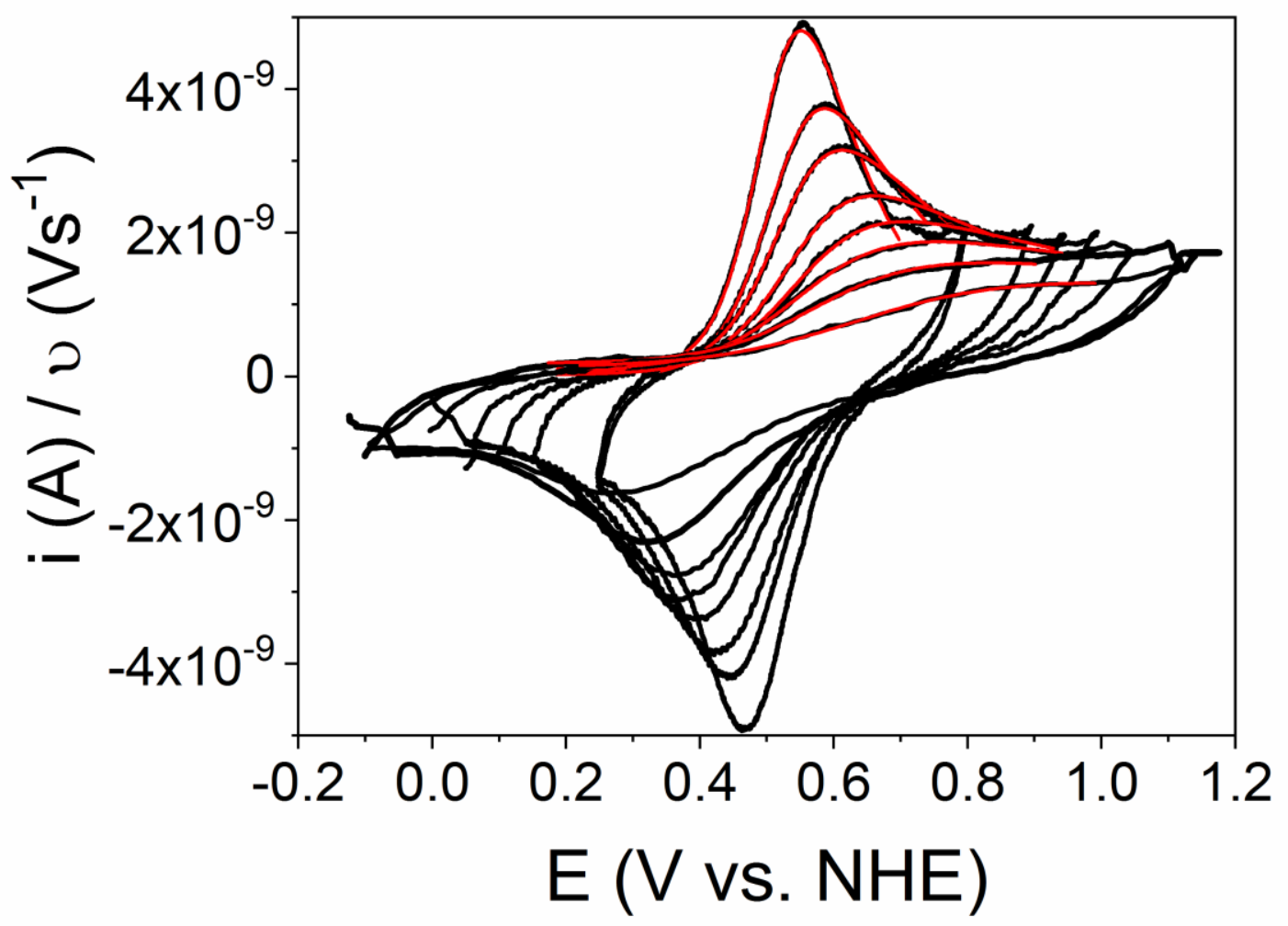

Figure 5. Scan rate dependence of the background-subtracted voltammetric response from a platinum electrode covered with phenol monolayer at pH 9.6 in $0.1 \mathrm{M} \mathrm{K}_{2} \mathrm{SO}_{4}$ buffered with $10 \mathrm{mM} \mathrm{Na}_{2} \mathrm{HPO}_{4}$ and $\mathrm{H}_{3} \mathrm{BO}_{3}$. The current response has been normalized to the scan rate for clarity and the data shown are from scan rates $100,303,500,1000$, $1600,2500,4000$ and $640010000 \mathrm{Vs}^{-1}$. The red lines are fits to the Equation derived from a steady state model (see text). 


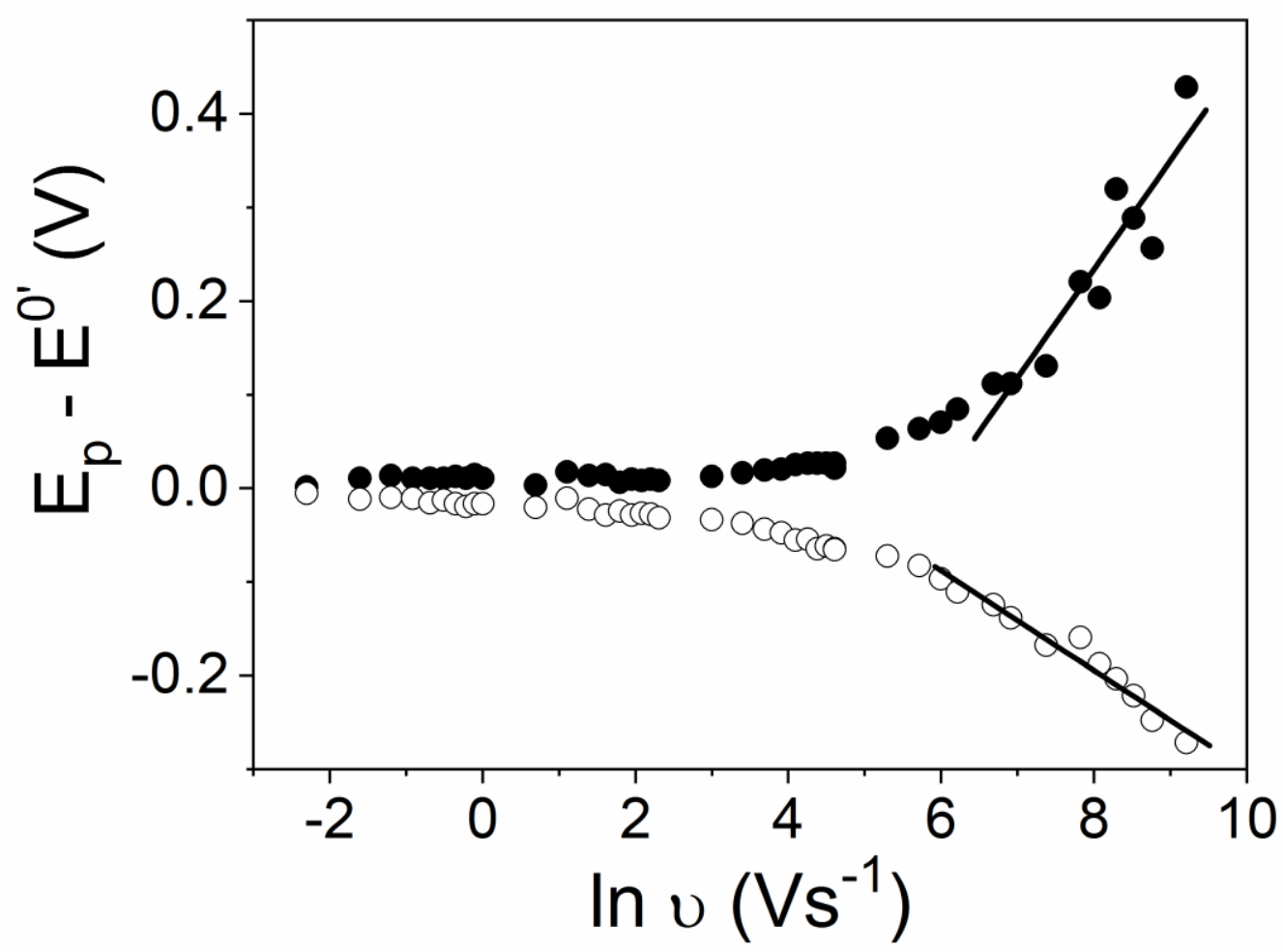

Figure 6. Peak over-potentials evaluated from cyclic voltammetry as a function of scan rate for the oxidative scan (solid circles) and the reductive scan (open circles). The conditions were the same as in Figure 5. The solid lines are linear fits to the high scanrate data.

Figure 5 shows typical scan rate dependence data for the phenol monolayer deposited on platinum at $\mathrm{pH} 9.6$ for scan rates between $100 \mathrm{Vs}^{-1}$ and $10000 \mathrm{Vs}^{-1}$. From the voltammograms, the peak over-potential was determined and the corresponding data are shown in Figure 6 as function of the logarithm of the scan rate. The data at scan rates where the peak over-potential was more than $100 \mathrm{mV}$ was fitted to a straight line and the formal rate constants were evaluated from the intercept with the $\mathrm{x}$-axis using the relevant Equation in Table 1. This was done for both the oxidative scan and the reductive scan at different $\mathrm{pH}$ values in the range between 8.5 and 11 . At all $\mathrm{pH}$-values the evaluated rate constant from the 
oxidative scan was slightly higher than the rate constants evaluated from the reductive scan

(Figure 7). This could possibly be due to difficulties in defining the peak potential in the oxidative case. As can be seen in Figure 5, the oxidation peak becomes broad and ill-defined at high scan rates. This could also explain the large scattering in the evaluated peak over potentials in Figure 6.

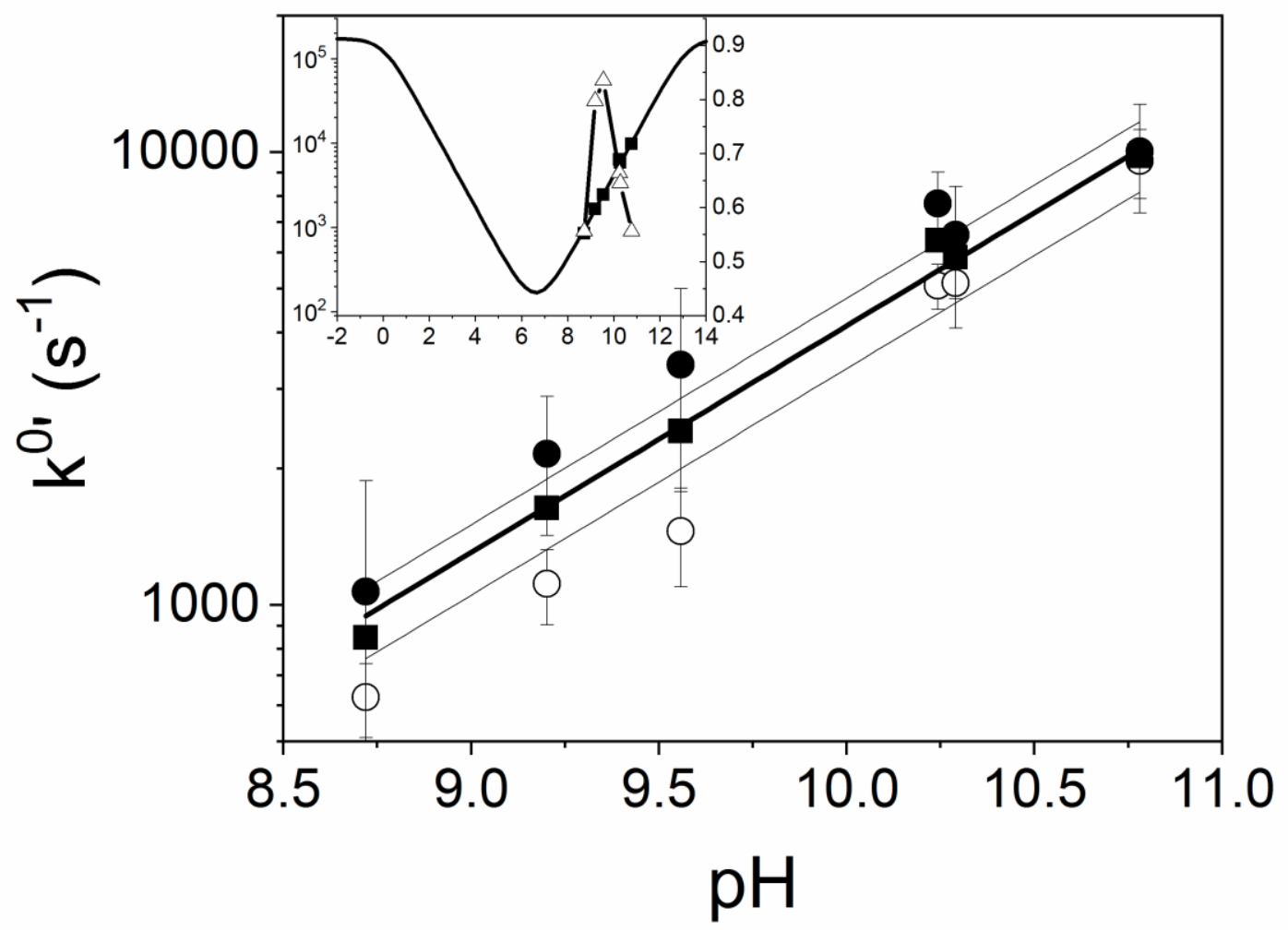

Figure 7. Evaluated formal rate constants from the oxidative scan (solid circles), the reductive scan (open circles) and the average of the two (solid squares) as a function of pH. Error bars have been included for the data from the oxidative and the reductive scan and corresponds to $99 \%$ confidence interval as evaluated from the linear regression analysis of scan rate dependence data (Figure 6). The thick line shows a fit to Equation 5 of the average formal rate constant and the thin lines are the corresponding fit of the data from the reductive and the oxidative scans. The inset shows a simulation of Equation 4 using the data from the fit at an extended pH range together with 
experimentally determined rate constants and the corresponding $\alpha$-values (triangles). In the simulation $\mathrm{k}_{1}^{0}$ has been set equal to $\mathrm{k}_{2}^{0}$ and $\mathrm{pKa}$ has been set to zero.

The $\mathrm{pH}$-dependence of the average formal rate constant gave good agreement with Equation 5 and a fit to this function (solid line Figure 7) resulted in a standard rate constant for the tyrosinate redox reaction $\left(\mathrm{k}_{2}^{0}\right)$ of $1.7^{*} 10^{5} \mathrm{~s}^{-1}$. In the fit the $\mathrm{pK}_{\mathrm{a}}$ value was locked to the $\mathrm{pK}_{\mathrm{a}}$ value determined from the $\mathrm{pH}$-dependence of the formal potential (Figure 4). From the scanrate dependence data the transfer coefficient at the formal potential was evaluated from the ratio between the intercepts of the linear fit for the oxidative and the reductive reaction according to the procedure described in ref. [38]. The resulting $\alpha$-values were at all $\mathrm{pH}$ values above 0.5 and showed a marked $\mathrm{pH}$ dependence with a maximum around $\mathrm{pH} 9.5$ (inset Figure 7). It is interesting to note that the inclusion of a potential-dependent transfer coefficient predicts a pH-dependence of the transfer coefficient at the formal potential that is quantitatively similar to the observed $\mathrm{pH}$ dependence. [23-25] For completeness the inset in Figure 7 shows a simulation of the expected $\mathrm{pH}$ dependence of the formal potential at an extended $\mathrm{pH}$ range using Equation 4. In this simulation the determined standard rate constant for $\mathrm{k}_{2}^{0}$ was used for both $\mathrm{k}_{2}^{0}$ and for $\mathrm{k}_{1}^{0}$ since no data are available to determine the standard rate constant for the fully protonated species. The $\mathrm{pK}_{\mathrm{a}}$-value for the phenol radical has been arbitrarily set to zero. The formal rate constant shows a deep minimum mid-way between the $\mathrm{pK}_{\mathrm{a}}$-values for the oxidized and the reduced species.

\subsection{Evaluation of kinetic parameters using a steady state approach}

Although the pre-equilibrium model does seem to account well for the observed formal rate constants evaluated from the scan rate dependence of the peak over potential, this model cannot account for the shape of the voltammograms. From Figure 5 it is evident that the 
electrochemistry is more complicated than the pre-equilibrium model predicts. Firstly, the normalized peak current decreases as the scan rate increases (Figure 5) in clear contradiction with the expression for the peak current given for the pre-equilibrium model in Table 1 . This effect is particularly evident at low $\mathrm{pH}$ but was observed at all values. Secondly, at scan rates where the reaction is kinetically controlled the peaks become much broader than anticipated from the pre-equilibrium model. We have therefore derived equations to evaluate cyclic voltammetry data using a steady state model in order to better model the data. Since, at $\mathrm{pH}$ values below the phenol $\mathrm{pK}_{\mathrm{a}}$, the deprotonation rate must be less than the rate of protonation and the rate constant for oxidation of the phenolate is higher than the rate constant for its reduction, a steady-state treatment of the phenolate is always valid under these conditions. For the oxidative scan the following also applies: Since the reaction is kinetically controlled at high scan rates the reduction rate must be negligible compared to the oxidation and can therefore be fully ignored in the kinetic analysis. The observed rate constant is then given by Equation 6 and the current response for an oxidative voltammetric scan is given by Equation 7 (See supporting information for the derivation of the functions). (For the re-reduction scan a corresponding current response function could not be derived since in this case both the reduction and the oxidation reaction have to be taken into account).

$$
\begin{aligned}
& k_{O x}=\frac{k_{2}^{0} e^{\frac{(1-\alpha) F}{R T}\left(E-E_{2}^{0}\right)} k_{2 d}}{k_{-2 d^{1}} 10^{-p H}+k_{2}^{0} e^{\frac{(1-\alpha) F}{R T}\left(E-E_{2}^{0}\right)}} \\
& i(E)=\frac{F A \Gamma_{R e d}^{0} k_{2 d} k_{2}^{0} e^{\frac{(1-\alpha) F}{R T}\left(E-E_{2}^{0}\right)}}{k_{-2 d^{1}} 10^{-p H}+k_{2}^{0} e^{\frac{(1-\alpha) F}{R T}\left(E-E_{2}^{0}\right)}}\left[\frac{k_{-2 d} 10^{-p H}+k_{2}^{0} e^{\frac{(1-\alpha) F}{R T}\left(E-E_{2}^{0}\right)}}{k_{-2 d} 10^{-p H}}\right]^{-\left(\frac{R T k_{2 d}}{(1-\alpha) F v}\right)}
\end{aligned}
$$

With this function the voltammetric response for the oxidation scan could be fully reproduced at all $\mathrm{pH}$-values used and at all scan-rates above $100 \mathrm{Vs}^{-1}$. This is exemplified at 
pH 9.6 in Figure 5 where the solid red lines are fits of the voltammograms to Equation 7. In the fit the value for $\mathrm{E}_{2}^{0}$ was fixed to the value obtained from the data in Figure 4 and the term $\mathrm{k}_{-2 \mathrm{~d}}$ was replaced by $\mathrm{k}_{2 \mathrm{~d}} / \mathrm{K}_{\mathrm{a}}$ from the proton equilibrium requirement to reduce the number of free parameters. An additional, constant term was added to Equation 7 in the fit to account for any capacitive currents uncompensated by the background subtraction procedure. From the fit the rate constants for deprotonation $\left(\mathrm{k}_{\mathrm{d} 2}\right)$, the standard rate constant for tyrosinate oxidation $\left(\mathrm{k}_{2}^{0}\right)$ and the transfer coefficients were evaluated (Table S1). The protonation rate constant $(\mathrm{k}$ 2d) was determined from the evaluated deprotonation rate-constant and the pKa-value for the phenol. All data reported below are average values evaluated from fits to voltammograms at several scan rates where the peak over-potential is more than $100 \mathrm{mV}$.

Figure 8 shows the standard rate constants for phenolate oxidation evaluated at different $\mathrm{pH}$ values together with the corresponding transfer coefficients. The exchange rate constant shows no statistically verified trend at $95 \%$ confidence with $\mathrm{pH}$, although the high $\mathrm{pH}$ data seem to give lower values, but scatters between $5^{*} 10^{4} \mathrm{~s}^{-1}$ and $6^{*} 10^{5} \mathrm{~s}^{-1}$ with an average value of $3 * 10^{5} \mathrm{~s}^{-1}$. A large scattering of the data is probably due to the extrapolation from the formal potential to the standard potential for phenolate redox reaction involved in the fit. This is particularly true for the low-pH data as the extrapolation is longer at these values of $\mathrm{pH}$. Also the transfer coefficients show a $\mathrm{pH}$-dependence that followed the same trend as the rate constants. The $\mathrm{pH}$ dependence of the transfer coefficient was however not statistically significant at $95 \%$ confidence and the average value was 0.6 . 


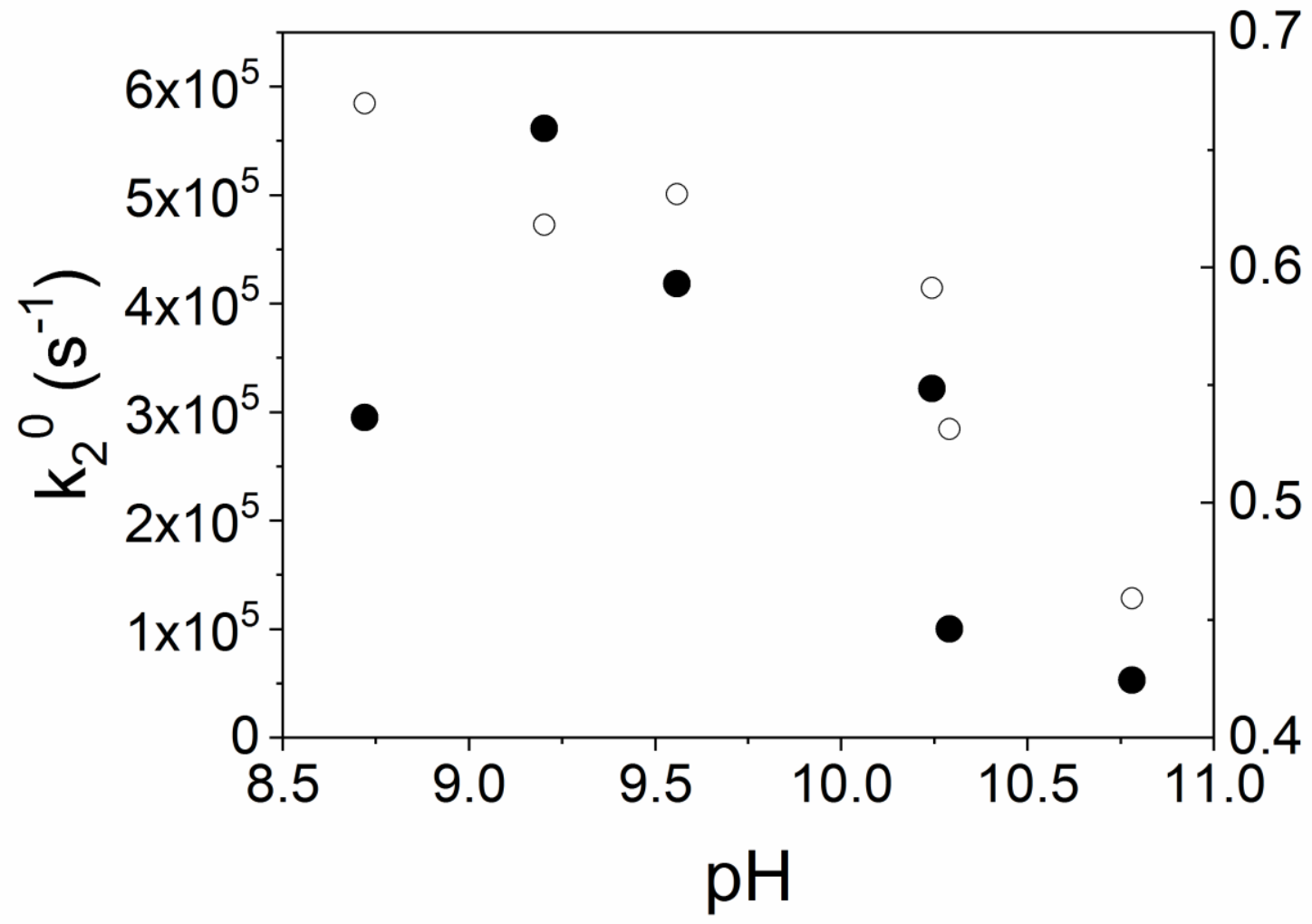

Figure 8. Standard rate constants for tyrosinate oxidation evaluated from fitting cyclic voltammograms to the steady state model (see text) as function of $\mathrm{pH}$ (solid circles) together with the corresponding transfer coefficient (open circles).

When comparing these results with the standard rate constant for tyrosinate oxidation evaluated from the steady state model, the agreement is fairly good, $\mathrm{k}_{2}^{0}=3 * 10^{5} \mathrm{~s}^{-1}$ for the steady state model and $1.7 * 10^{5} \mathrm{~s}^{-1}$ for the pre-equilibrium model. As in the pre-equilibrium model the expected scan rate dependence of the peak over-potential is a linear increase with scan rate and the scan rate dependence is identical with $\mathrm{k}^{0,}=\mathrm{k}^{0}{ }_{2} \mathrm{k}_{2 \mathrm{~d}} / \mathrm{k}_{-\mathrm{d}} 10^{-\mathrm{pH}}$. This is however in contradiction to Equation 5 and the $\mathrm{pH}$-dependence of the formal exchange rate constant does not agree with the steady state model. This model predicts a much stronger $\mathrm{pH}$ dependence of the rate constant evaluated from the scan rate dependence of the peak overpotential as outlined above, with a one decade increase per $\mathrm{pH}$ unit. From Figure 5 it is 
evident that the peak at high scan rates becomes broad and ill-defined and hence that the peak potential is a blunt tool to evaluate kinetic data. This is also apparent from the scattering of the peak over-potentials for the oxidation process in Figure 6. We therefore believe that the apparent agreement to the pre-equilibrium model that is shown by the $\mathrm{pH}$-dependence of the formal rate constants is erroneous and that the seemingly reasonable agreement to this model is not sufficient for evaluating its aptness.

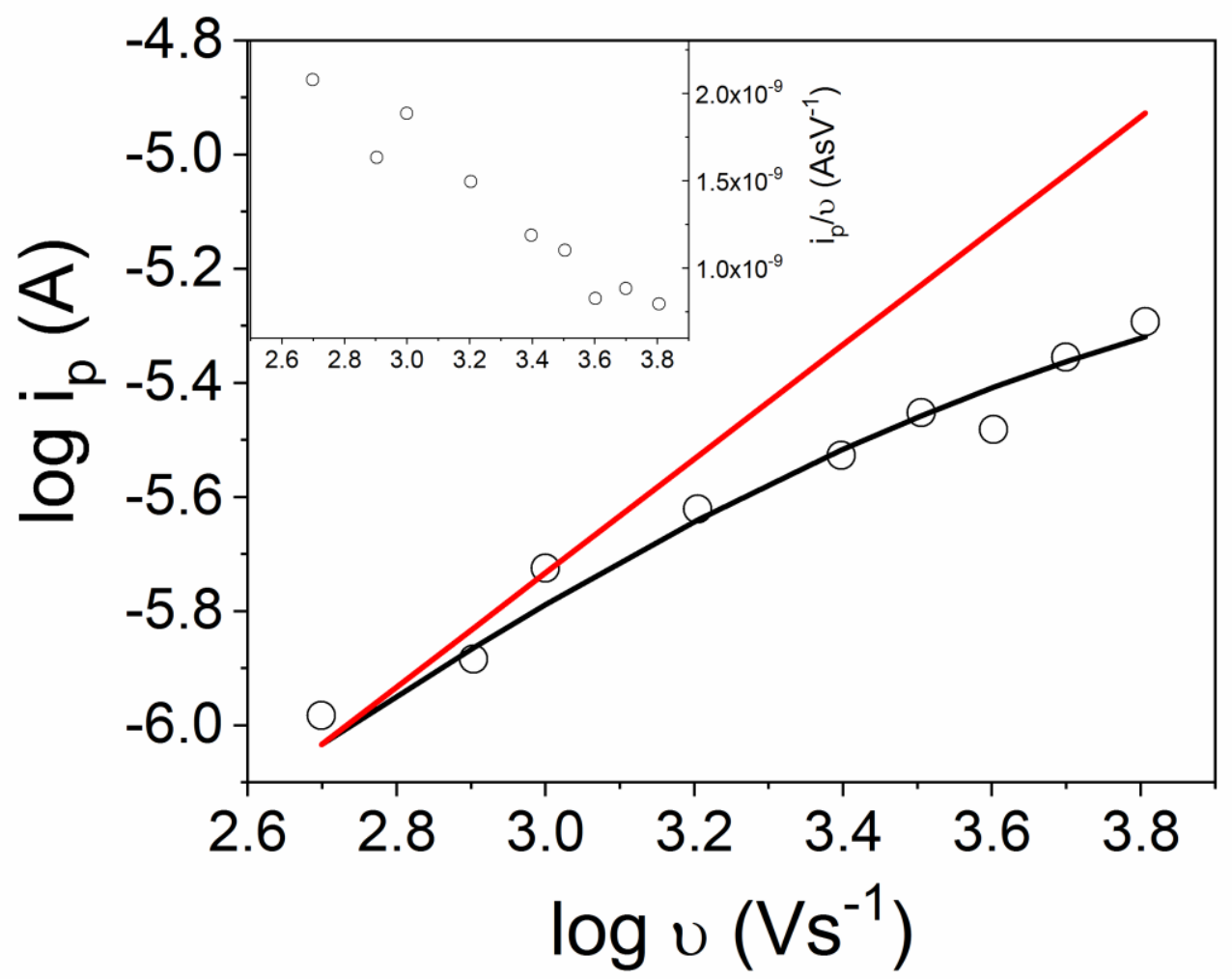

Figure 9. Peak currents for the oxidative wave as a function of scan rate at pH 9.6. The solid black line is a fit to the expected scan rate dependence of the peak current using the steady state model (see text) and the solid red line is the expected variation of the peak current based on the pre-equilibrium model. The inset shows the scan rate dependence of the peak current normalized to the scan rate. 
As seen in Figure 5 the peak current does not increase linearly with scan rate at high scan rates as the pre-equilibrium model predicts (Figure 5, solid red line). (Note that the peak current for the pre-equilibrium model is expected to decrease with scan rate if a potential dependent transfer coefficient is included. This deviation from linearity is, however, much weaker than the observed deviation). Instead a clear deviation from linearity is observed (Figure 9). The deviation from the pre-equilibrium model can be seen more clearly in the inset of Figure 9 which shows the peak current normalized to the scan rate. A clear decrease in normalized peak current is observed as the scan rate is increased. Similar behavior has previously been reported for the proton coupled electron transfer in an Osmium-aqua complex studied by Finklea et.al. [39] Such scan rate dependence cannot be accounted for by preequilibrium models that predict a constant normalized peak current. At lower scan rates a constant normalized peak current is observed however (data not shown) possibly indicating that the pre-equilibrium model is valid at lower over-potentials. In contrast to the preequilibrium model, the steady-state model predicts that the scan rate dependence of the peak current carries kinetic information (Table 1). By fitting the peak current to the equation given in Table 1 (Figure 9 solid line) the deprotonation rate constant could be determined and the resulting rate constants are presented in Figure 10 as function of $\mathrm{pH}$ together with the corresponding rate constants evaluated from fitting the voltammograms as described above. In both cases the logarithm of the deprotonation rate constant increases linearly with $\mathrm{pH}$ and the two procedures for evaluating the rate constant give excellent agreement. 


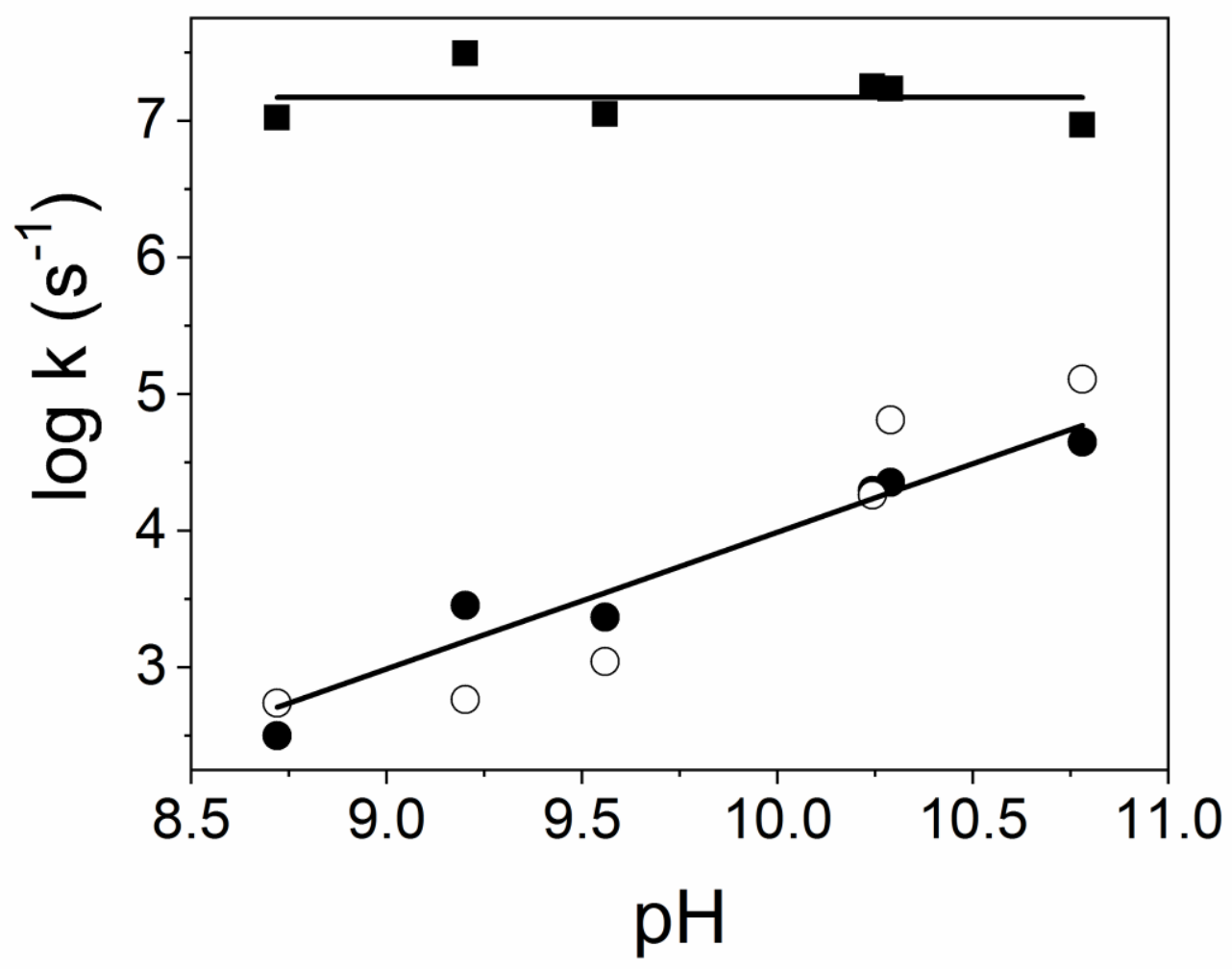

Figure 10. Evaluated rate constants for the proton transfer reactions as function of $\mathrm{pH}$. Circles correspond to the deprotonation rate constant $\left(k_{2 d}\right)$ and the squares to the protonation rate constant $\left(k_{-2 d}\right)$. The solid circles were evaluated from fitting voltammograms at different scan rates and the open circles from fits of the peak current as function of scan rate.

From the $\mathrm{pH}$ dependence of the deprotonation constant it is clear that the reaction is dominated by deprotonation by $\mathrm{OH}^{-}$(right panel Figure 1). The evaluated deprotonation rate constant is thus a pseudo first order rate constant with respect to $\left[\mathrm{OH}^{-}\right]$. It is important to note here that the derived Equations for the steady-state model are valid irrespective of the dominating deprotonation path (see supporting information). The true deprotonation rate constant $\left(\mathrm{k}^{0}{ }_{2 \mathrm{~d}}\right)$ was extracted from the slope of the fit of the data in Figure 10 to a straight line. From the data extracted from fitting the voltammograms the deprotonation rate constant 
was $9.8^{*} 10^{7} \mathrm{M}^{-1} \mathrm{~s}^{-1}$ and from the peak current data the corresponding value was $9.4^{*} 10^{7} \mathrm{M}^{-1} \mathrm{~s}^{-}$ 1. This is orders of magnitudes less than diffusion controlled which might be due to the steric hindrance of the bulky tert-butyl groups around the phenol OH-group. Since deprotonation is dominated by proton extraction by $\mathrm{OH}^{-}$the protonation reaction is dominated by the $\mathrm{pH}$ independent protonation by water. The rate constant for this reaction was determined from the pseudo first order deprotonation rate constants to $\mathrm{k}_{-2 \mathrm{~d}}{ }^{\prime}=1.5^{*} 10^{7} \mathrm{~s}^{-1}$ (Figure 10).

With all involved rate constants at hand we are now in a position to judge the validity of the two models presented. In the pre-equilibrium model the assumption is that all proton transfer reactions are fast compared to the electron transfer reactions $\left(k_{2 d}>>k_{2}\right.$ and $\left.k_{-2 d}>>k_{2}\right)$, whilst in the steady state model it is assumed that the reactions forming the intermediate state, in this case the phenolate, is slower than its consumption, i.e. $k_{-2 d}+k_{2}>k_{2 d}$. Since at all values of $\mathrm{pH}$ investigated the pseudo first order deprotonation rate constant $\mathrm{k}_{2 \mathrm{~d}}$ is less than the exchange rate constant $\left(\mathrm{k}_{2}\right)$, the requirement for the pre-equilibrium model is clearly not met. On the other hand, since both the protonation and the oxidation reaction at all $\mathrm{pH}$ values investigated are faster than the rate of deprotonation, the steady state approach is valid. A major drawback with this model is that analytical expressions describing the cyclic voltammetry of the rereduction process cannot be attained. Other methods of investigation must therefore be used to get more information on the proton-coupled electron transfer reaction from the phenol monolayers investigated in this study.

\section{Conclusions}

Tert-butyl protected phenols have been covalently attached to self-assembled thiol monolayers and the thermodynamics and kinetics of the proton-coupled electron transfer from these layers have been investigated in water solution as function of $\mathrm{pH}$. The results are consistent with a $1 \mathrm{e} 1 \mathrm{H}$ redox system and the kinetics has been modeled using two different 
approaches, a pre-equilibrium approach and a steady state approach. In the pre-equilibrium model rapid proton transfer reactions ensures that acid-base equilibrium is at all times established and in the steady state approach it is instead assumed that the concentration of intermediate species in the reaction are never built up. We have shown that the behavior of the phenol monolayer is inconsistent with the pre-equilibrium model, which has been extensively used in the literature, although apparent and misleading agreement with this model is observed. For the steady state model Equations to describe voltammetric responses have been derived and the behavior of the phenol monolayers was accurately described using this model.

\section{Supporting Information Available}

Derivation of cyclic voltammetry response with the steady state model and Table S1 with fit parameters.

\section{Acknowledgements}

This project was supported by a Marie Curie Intra-European Fellowships within the $6^{\text {th }}$ European Community Framework Program, the Swedish Research Council, Science Foundation Ireland under the Biomedical Diagnostics Institute, the EU STRP networks Solar$\mathrm{H}$ and Solar $\mathrm{H} 2$ and the ANR program PROTOCOLE. This publication has emanated from research supported in part by a research grant from Science Foundation Ireland (SFI) under Grant Number 16/RC/3948 and co-funded under the European Regional Development Fund and by FutureNeuro industry partners.

\section{References}

[1] J. Stubbe, W.A. van der Donk, Protein Radicals in Enzyme Catalysis, Chem. Rev. 98(7) (1998) 2661-2662.

[2] R.I. Cukier, D.G. Nocera, PROTON-COUPLED ELECTRON TRANSFER, Annu. Rev. Phys. Chem. 49(1) (1998) 337-369. 
[3] J.M. Mayer, PROTON-COUPLED ELECTRON TRANSFER: A Reaction Chemist's View, Annu. Rev. Phys. Chem. 55(1) (2004) 363-390.

[4] M.H.V. Huynh, T.J. Meyer, Proton-Coupled Electron Transfer, Chem. Rev. 107(11) (2007) 5004-5064.

[5] C. Costentin, M. Robert, J.-M. Savéant, Adiabatic and Non-adiabatic Concerted Proton-Electron Transfers. Temperature Effects in the Oxidation of Intramolecularly Hydrogen-Bonded Phenols, J. Am. Chem. Soc. 129(32) (2007) 9953-9963.

[6] I.J. Rhile, T.F. Markle, H. Nagao, A.G. DiPasquale, O.P. Lam, M.A. Lockwood, K. Rotter, J.M. Mayer, Concerted Proton-Electron Transfer in the Oxidation of HydrogenBonded Phenols, J. Am. Chem. Soc. 128(18) (2006) 6075-6088.

[7] L.I. Krishtalik, pH-dependent redox potential: how to use it correctly in the activation energy analysis, Biochim. Biophys. Acta 1604(1) (2003) 13-21.

[8] M. Sjödin, S. Styring, H. Wolpher, Y. Xu, L. Sun, L. Hammarström, Switching the Redox Mechanism: Models for Proton-Coupled Electron Transfer from Tyrosine and Tryptophan, J. Am. Chem. Soc. 127(11) (2005) 3855-3863.

[9] T. Irebo, S.Y. Reece, M. Sjödin, D.G. Nocera, L. Hammarström, Proton-Coupled Electron Transfer of Tyrosine Oxidation: Buffer Dependence and Parallel Mechanisms, J. Am. Chem. Soc. 129(50) (2007) 15462-15464.

[10] C.W. Hoganson, G.T. Babcock, A Metalloradical Mechanism for the Generation of Oxygen from Water in Photosynthesis, Science 277(5334) (1997) 1953-1956.

[11] C. Aubert, M.H. Vos, P. Mathis, A.P. Eker, K. Brettel, Intraprotein radical transfer during photoactivation of DNA photolyase, Nature 405(6786) (2000) 586-90.

[12] G.T. Babcock, How oxygen is activated and reduced in respiration, Proceedings of the National Academy of Sciences 96(23) (1999) 12971-12973.

[13] A.J. Bard, I. Rubenstein, Electroanalytical chemistry. a series of advances Vol. 19, (1996).

[14] E. Laviron, Theoretical study of a $1 \mathrm{e}, 1 \mathrm{H}+$ surface electrochemical reaction (fourmember square scheme) when the protonation reactions are at equilibrium, Journal of Electroanalytical Chemistry and Interfacial Electrochemistry 109(1) (1980) 57-67.

[15] E. Laviron, Electrochemical reactions with protonations at equilibrium: Part IV. General considerations on the reaction sequence, Journal of Electroanalytical Chemistry and Interfacial Electrochemistry 130 (1981) 23-29.

[16] E. Laviron, Electrochemical reactions with protonations at equilibrium: Part II. The 1e, 1 $\mathrm{H}+$ reaction (four-member square scheme) for a heterogeneous reaction, Journal of Electroanalytical Chemistry and Interfacial Electrochemistry 124(1) (1981) 1-7.

[17] E. Laviron, Electrochemical reactions with protonations at equilibrium: Part VI. The homogeneous electron exchange reaction between a monoelectronic and $\mathrm{A} 1 \mathrm{e}, 1 \mathrm{H}+$ system, Journal of Electroanalytical Chemistry and Interfacial Electrochemistry 137(1) (1982) 1-15.

[18] E. Laviron, Electrochemical reactions with protonations at equilibrium Part V. THE 1 e, $1 \mathrm{H}+$ homogeneous isotopic exchange reaction, Journal of Electroanalytical Chemistry and Interfacial Electrochemistry 134(2) (1982) 205-212.

[19] E. Laviron, L. Roullier, Electrochemical reactions with protonations at equilibrium: Part IX. Comparison between the surface and heterogeneous electrochemical rate constants in the system phenazine/dihydrophenazine, Journal of Electroanalytical Chemistry and Interfacial Electrochemistry 157(1) (1983) 7-18.

[20] R.M. Haddox, H.O. Finklea, Proton coupled electron transfer of galvinol in selfassembled monolayers, J. Electroanal. Chem. 550-551 (2003) 351-358. 
[21] E. Laviron, Electrochemical reactions with protonations at equilibrium: Part X. The kinetics of the p-benzoquinone/hydroquinone couple on a platinum electrode, Journal of Electroanalytical Chemistry and Interfacial Electrochemistry 164(2) (1984) 213-227.

[22] S.-X. Guo, S.W. Feldberg, A.M. Bond, D.L. Callahan, P.J.S. Richardt, A.G. Wedd, Systematic Approach to the Quantitative Voltammetric Analysis of the FeIII/FeII Component of the [a2-Fe(OH2)P2W17O61]7-/8- Reduction Process in Buffered and Unbuffered Aqueous Media, The Journal of Physical Chemistry B 109(43) (2005) 20641-20651.

[23] H.O. Finklea, R.M. Haddox, Coupled electron/proton transfer of galvinol attached to SAMs on gold electrodes, PCCP 3(16) (2001) 3431-3436.

[24] H.O. Finklea, Consequences of a potential-dependent transfer coefficient in ac voltammetry and in coupled electron-proton transfer for attached redox couples, J. Electroanal. Chem. 495(2) (2001) 79-86.

[25] H.O. Finklea, Theory of Coupled Electron-Proton Transfer with Potential-Dependent Transfer Coefficients for Redox Couples Attached to Electrodes $\dagger$, The Journal of Physical Chemistry B 105(37) (2001) 8685-8693.

[26] M. Eigen, Proton Transfer, Acid-Base Catalysis, and Enzymatic Hydrolysis. Part I: ELEMENTARY PROCESSES, Angewandte Chemie International Edition in English 3(1) (1964) 1-19.

[27] R.P. Bell, The Proton in Chemistry, (2013). DOI: 10.1007/978-1-4757-1592-7

[28] M. Gutman, E. Nachliel, The dynamics of proton exchange between bulk and surface groups, Biochimica et Biophysica Acta (BBA) - Bioenergetics 1231(2) (1995) 123-138.

[29] P. International Union of, C. Applied, D. Commission on Equilibrium, E.P. Serjeant, B. Dempsey, P. International Union of, C. Applied, D. Commission on Electrochemical, Ionisation constants of organic acids in aqueous solution, Pergamon Press, Oxford; New York, 1979.

[30] S. Trasatti, O.A. Petrii, Real surface area measurements in electrochemistry, J. Electroanal. Chem. 327(1) (1992) 353-376.

[31] M.M. Walczak, D.D. Popenoe, R.S. Deinhammer, B.D. Lamp, C. Chung, M.D. Porter, Reductive desorption of alkanethiolate monolayers at gold: a measure of surface coverage, Langmuir 7(11) (1991) 2687-2693.

[32] a. L H Dubois, R.G. Nuzzo, Synthesis, Structure, and Properties of Model Organic Surfaces, Annu. Rev. Phys. Chem. 43(1) (1992) 437-463.

[33] C.D. Bain, J. Evall, G.M. Whitesides, Formation of monolayers by the coadsorption of thiols on gold: variation in the head group, tail group, and solvent, J. Am. Chem. Soc. 111(18) (1989) 7155-7164.

[34] J.P. Folkers, P.E. Laibinis, G.M. Whitesides, J. Deutch, Phase behavior of twocomponent self-assembled monolayers of alkanethiolates on gold, The Journal of Physical Chemistry 98(2) (1994) 563-571.

[35] C. Tommos, J.J. Skalicky, D.L. Pilloud, A.J. Wand, P.L. Dutton, De Novo Proteins as Models of Radical Enzymes, Biochemistry 38(29) (1999) 9495-9507.

[36] E.J. Land, G. Porter, E. Strachan, Primary photochemical processes in aromatic molecules. Part 6.-The absorption spectra and acidity constants of phenoxyl radicals, Transactions of the Faraday Society 57(0) (1961) 1885-1893.

[37] W.T. Dixon, D. Murphy, Determination of the acidity constants of some phenol radical cations by means of electron spin resonance, Journal of the Chemical Society, Faraday Transactions 2: Molecular and Chemical Physics 72(0) (1976) 1221-1230.

[38] E. Laviron, General expression of the linear potential sweep voltammogram in the case of diffusionless electrochemical systems, Journal of Electroanalytical Chemistry and Interfacial Electrochemistry 101(1) (1979) 19-28. 
[39] R.M. Haddox, H.O. Finklea, Proton-Coupled Electron Transfer of an Osmium Aquo Complex on a Self-Assembled Monolayer on Gold, The Journal of Physical Chemistry B 108(5) (2004) 1694-1700. 
Credit Author Statement:

Martin Sjödin: Conceptualization, Methodology, Formal analysis, Investigation, Data Curation, Writing - Original Draft, Writing - Review \& Editing, Visualization, Project administration, Funding acquisition Johan Hjelm: Conceptualization, Methodology, Writing - Review \& Editing A. William Rutherford: Resources, Writing - Review \& Editing, Supervision Robert Forster: Conceptualization, Methodology, Resources, Writing - Review \& Editing, Supervision, Project administration, Funding acquisition 


\section{Declaration of interests}

$\bigotimes$ The authors declare that they have no known competing financial interests or personal relationships that could have appeared to influence the work reported in this paper.

$\square$ The authors declare the following financial interests/personal relationships which may be considered as potential competing interests: 


\begin{tabular}{|c|c|c|}
\hline & Peak Current (A) & $\mathbf{E}_{\mathrm{p}}-\mathbf{E}^{0},(\mathrm{~V})$ \\
\hline $\begin{array}{l}\text { Pre-Equilibrium } \\
\text { model } \\
\text { (Oxidative Scan) }\end{array}$ & $\frac{(1-\alpha) n A F^{2} \Gamma v}{2.718 R T}$ & $\frac{R T}{(1-\alpha) n F} \ln \frac{(1-\alpha) n F}{R T k^{0^{\prime}}}-\frac{R T}{(1-\alpha) n F} \ln v$ \\
\hline $\begin{array}{l}\text { Pre-Equilibrium } \\
\text { model } \\
\text { (Reductive Scan) }\end{array}$ & $-\frac{\alpha n A F^{2} \Gamma v}{2.718 R T}$ & $-\frac{R T}{\alpha n F} \ln \frac{\alpha n F}{R T k^{0^{\prime}}}-\frac{R T}{\alpha n F} \ln v$ \\
\hline $\begin{array}{l}\text { Steady State } \\
\text { model } \\
\text { (Oxidative scan) }\end{array}$ & $\frac{F A \Gamma_{R e d}^{0} k_{2 d}(1-\alpha) F v}{R T k_{2 d}+(1-\alpha) F v}\left[1+\frac{(1-\alpha) F v}{R T k_{2 d}}\right]^{-\frac{R T k_{2 d}}{(1-\alpha) F v}}$ & $E_{2}^{0}-\frac{R T}{(1-\alpha) F} \ln \frac{k_{2}^{0} R T k_{2 d}}{(1-\alpha) F v k_{2 d} 10^{p K a_{2}-p H}}+\frac{R T}{(1-\alpha) F} \ln v$ \\
\hline
\end{tabular}




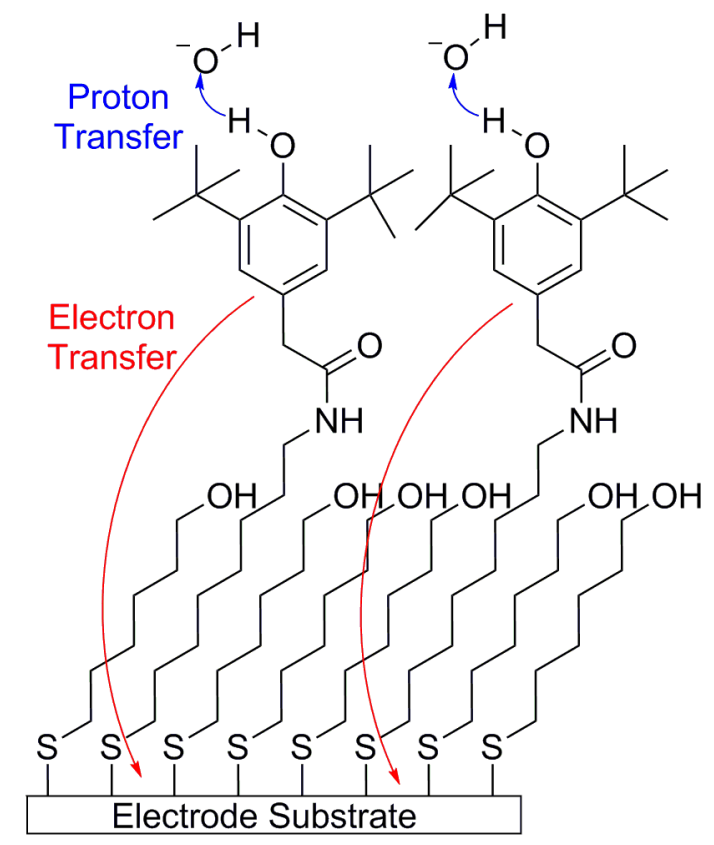




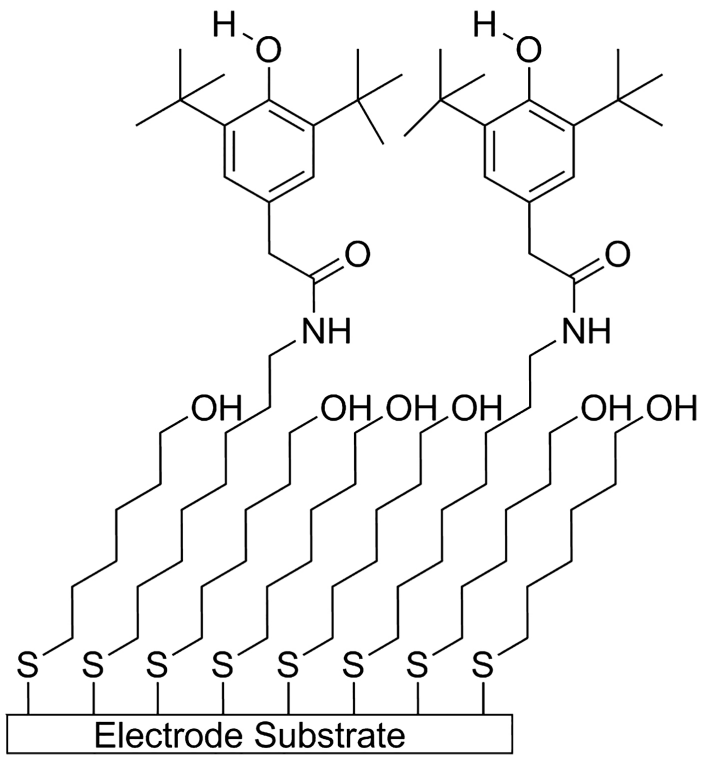

Figure 1 


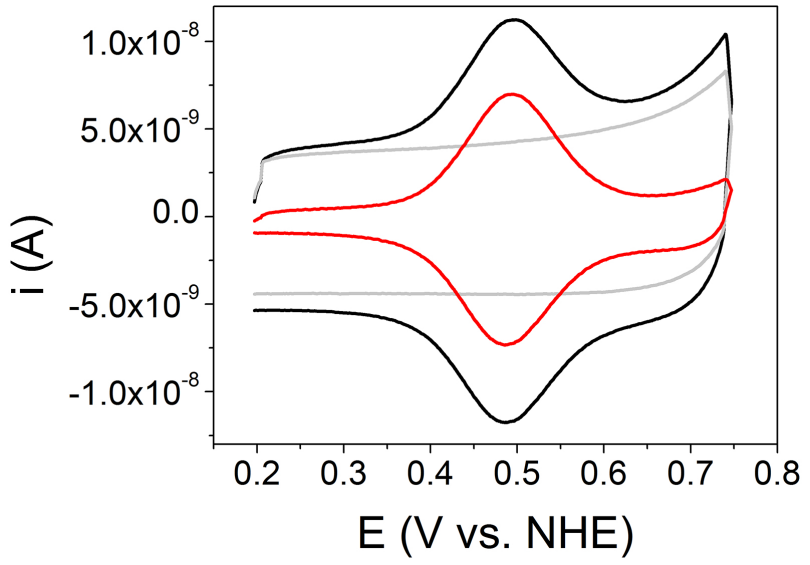

Figure 2 


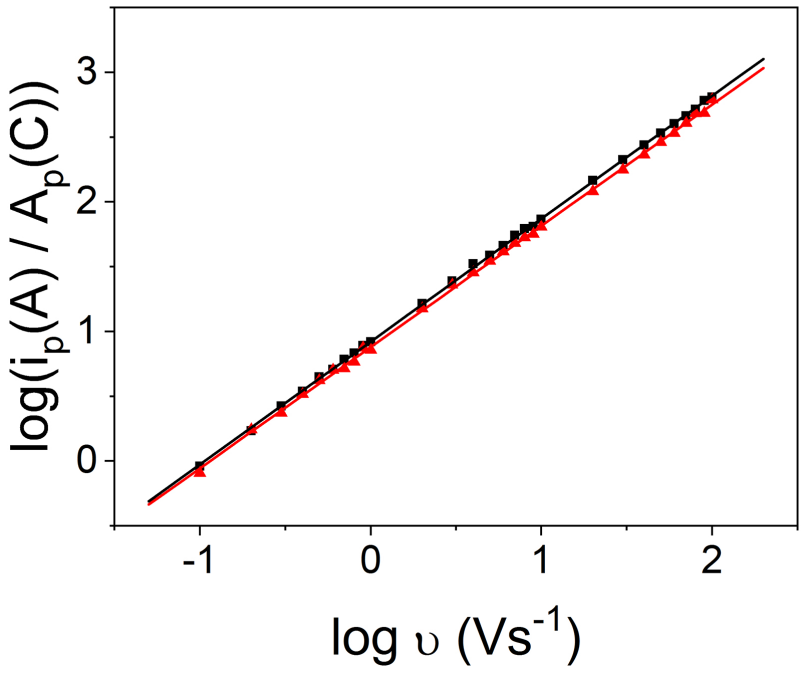

Figure 3 


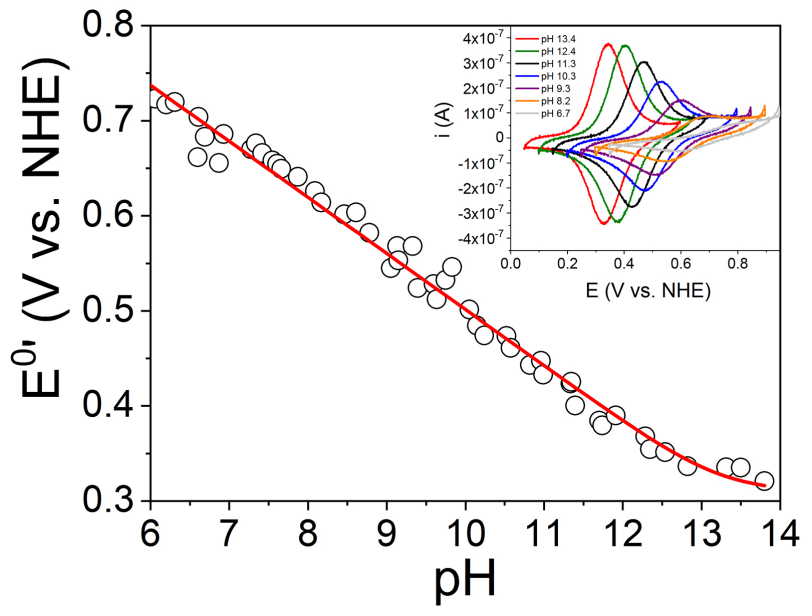

Figure 4 


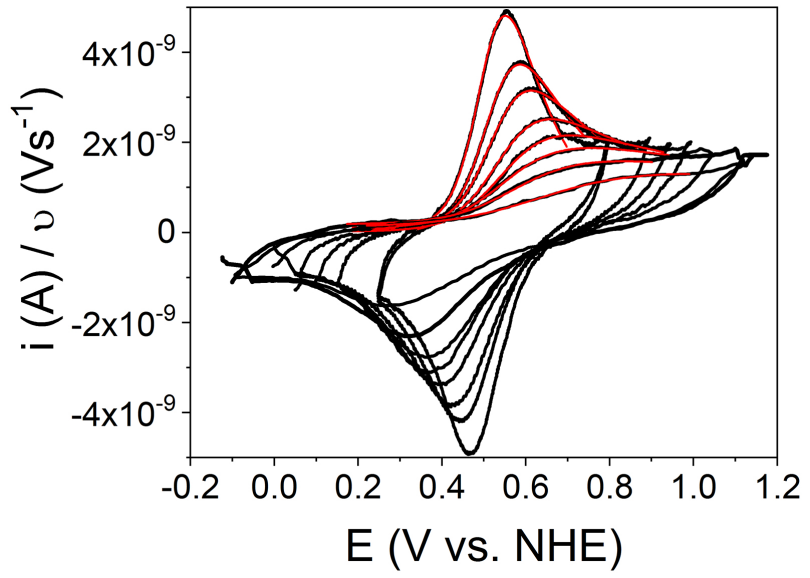

Figure 5 


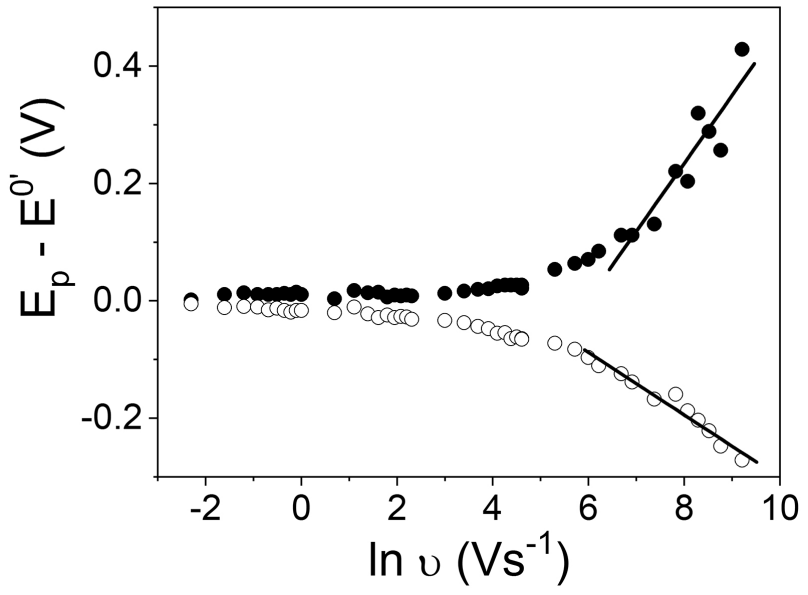

Figure 6 


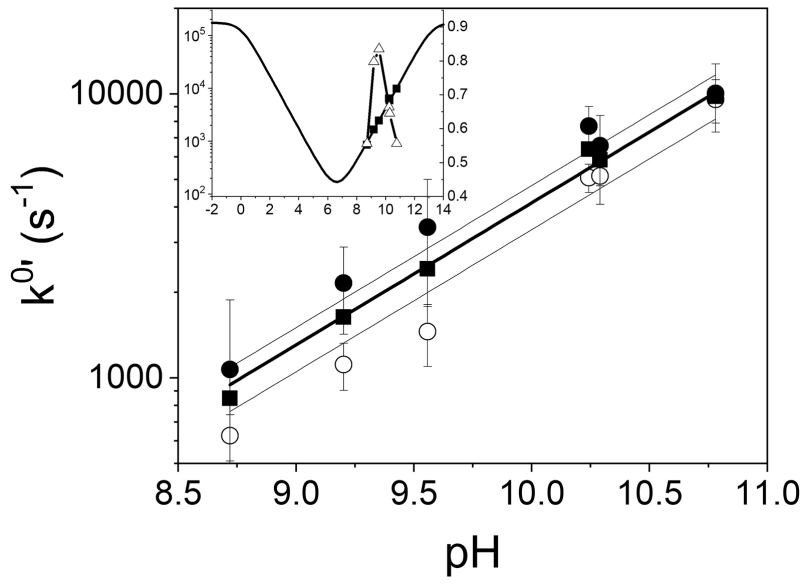

Figure 7 


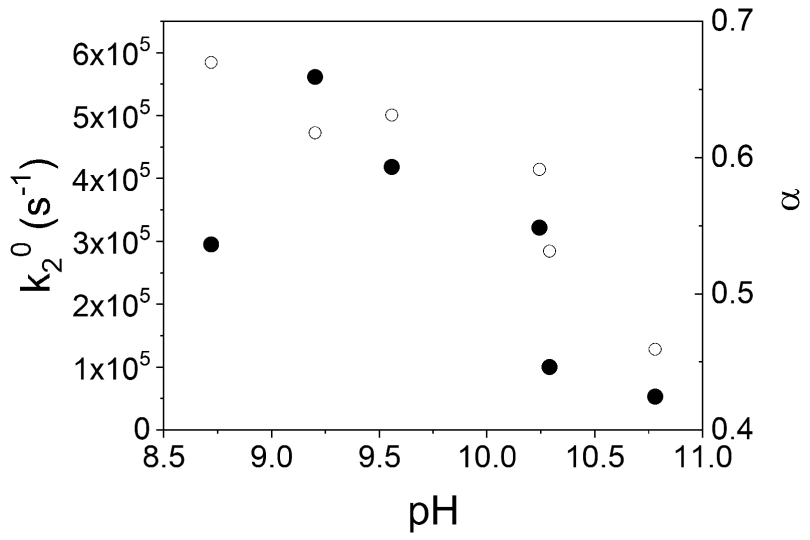

Figure 8 


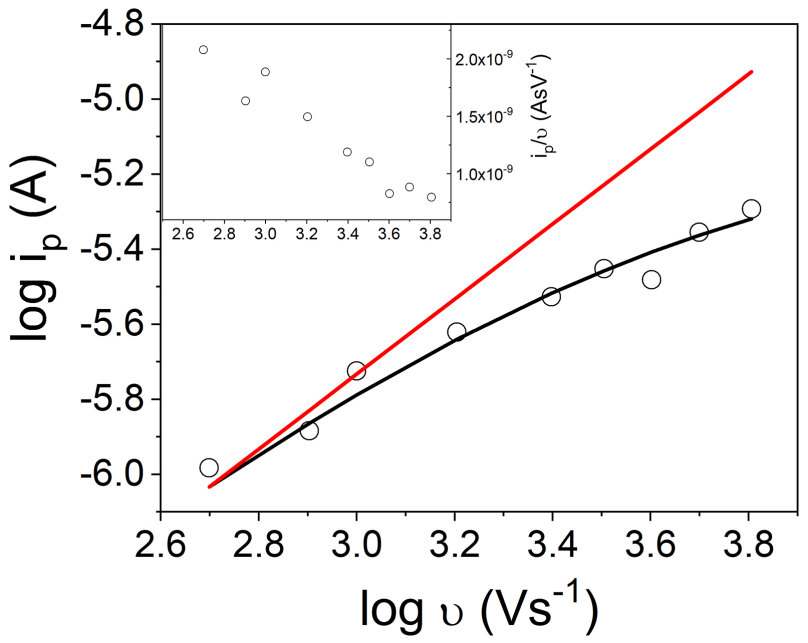

Figure 9 


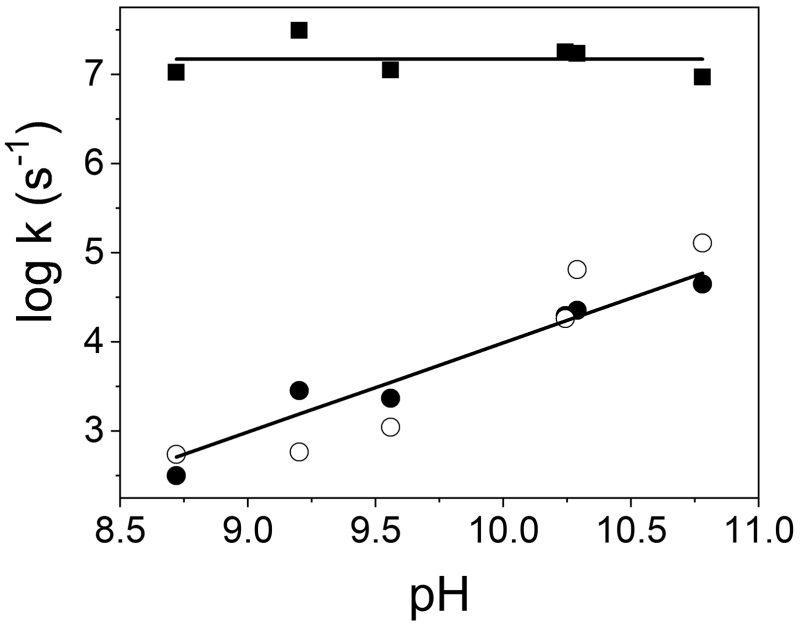

Figure 10 